\title{
Arbor
}

\section{Botánica y Evolución}

\author{
Margarita Moreno
}

Arbor CLXXII, 677 (Mayo), 59-99 pp.

Numerosos datos del campo de la Botánica (tanto paleo como neontológica) inciden sobre los puntos flacos del paradigma neodarwinista, cuestionando algunos de sus pilares básicos y proporcionando puntos de vista alternativos acerca de los tempos y modos de evolución. La puesta en común de saberes procedentes de distintas aproximaciones y de todos los niveles de la jerarquía biológica: desde el molecular hasta el ecosistémico, contrasta con el reduccionismo del paradigma dominante y parece estar produciendo nuevos y mejores frutos.

\section{Introducción: La Botánica y los estudios de evolución}

Es probable que las mayores contribuciones a la teoría evolutiva se deban más a zoólogos s.l. que a botánicos. Quizá poque los Animalia forman un grupo monofilético, relativamente reciente, amén de que la mayoría fosilizan bien, de suerte que se han podido establecer desde pronto filogenias fiables de sus estirpes; la existencià de éstas a su vez, ha permitido jugar con diferentes hipótesis acerca de cómo trabaja la evolución, de sus tempos y modos. "Cada organismo es el producto de su historia. Es necesario conocer su historia para entender su naturaleza» Olsen \& al. (1).

Por el contrario, la Botánica se ha ocupado tradicionalmente de una buena colección de organismos fotosintetizadores mas de los hongos que no lo son (precisamente lo que son es grupo hermano de los animales), abarcando desde las cianobacterias («inventoras» de la fotosíntesis oxigénica) y las «algas eucarióticas» (ese conjunto polifilético) hasta las 
plantas terrestres; es decir, cuatro de los cinco reinos reconocidos por Margulis \& Schwartz (2), que han desplegado su actividad a lo largo de c. 4.000 millones de años (= Ma): la totalidad del tiempo de la biosfera.

Además no se tuvo noticia del registro fósil más temprano prácticamente hasta la segunda mitad del siglo XX, siendo éste más difícil de datar y de interpretar (3) ya que sus componentes, tan diferentes a los actuales, se resisten al trabajo comparativo; y también resultaba menos inmediato el establecimiento de buenas filogenias «vegetales» a causa de que su morfología más simple se presta a un mayor contenido de homoplasia.

Quizá por todo ello, los botánicos se han visto poco estimulados a emprender trabajos sobre evolución y han participado apenas en los grandes debates que han sacudido a las teorías evolutivas: lamarckismo vs. darwinismo, gradualismo vs. abruptismo, adaptacionismo vs. neutralismo etc.; así por ejemplo, Rayner \& al. (4) se lamentan de que la evolución no haya estado presente en los círculos de los micólogos y casi lo mismo podría decirse del resto de la áreas que cubre la botánica. No obstante no han faltado importantes contribuciones, como las de Grant $(5,6)$, Stebbins $(7,8)$ o Niklas (9) aunque casi siempre referidas sólo a las plantas vasculares cuando no exclusivamente a las angiospermas.

Los mayores avances se han producido en el campo de la filogenia, en el que se ha pasado prácticamente de la (casi) nada al (casi) todo, arrollando entre medias a buena parte de los viejos paradigmas, confirmando otros y erigiendo nuevos: no se puede dudar actualmente de la naturaleza microbiana de mitocondrias y plastos primarios; de la condición plurigenómica de los eucariontes; de la polifilia de «las algas» y de lo irrazonable de estudiarlas separadas de sus parientes "protozoos». Igualmente entre las plantas terrestres se ha determinado con certeza el linaje algino del que proceden, y se avanza en el conocimiento de las relaciones entre sus grupos. Numerosos temas quedan aún sin resolver pero la disponibilidad actual de un registro fósil razobablemente nutrido a la vez que de hipótesis filogenéticas suficientemente buenas, permite ahora replantearse los viejos problemas, proponer para ellos nuevas interpretaciones, realizar nuevas síntesis y explorar los tópicos de la teoría evolutiva a la luz de los nuevos datos.

\section{Paradigma neodarwinista como punto de partida}

El último siglo ha contemplado el desarrollo del neodarwinismo hasta su conversión en paradigma hegemónico, aunque salpicado de fuertes 
polémicas que ponían en entredicho unos u otros de sus grandes pilares: el cambio evolutivo gradual, las micromutaciones como materia prima del cambio, la macroevolución como resultado sumario de la microevolución, la selección natural como fuerza creadora, etc.

Darwin (y posteriormente la escuela Neodarwinista) defendía que el cambio evolutivo se originaba mediante pequeñas diferencias individuales aparecidas (por azar) en cada generación de toda población, las cuales, gracias a la competencia entre fenotipos y al concurso de la selección natural, permanecerían o serían eliminadas; tales cambios, acumulados a lo largo de un tiempo suficiente, originarían otros mayores dando lugar a nuevos diseños o tipos principales, de suerte que la macroevolución «no sería más que una extrapolación y ampliación de los acontecimientos que tienen lugar en el seno de poblaciones y especies» (10), es decir, de la microevolución.

Pronto se cuestionó, desde el lado de la paleontología, la naturaleza gradual del cambio ya que el registro fósil no parecía contener los «tipos intermedios» esperables de un proceso de variación continua; más parecía dar la razón a los postulados de Cuvier acerca de sucesivos desastres seguidos de sucesivas creaciones, cada una con tipos bien diferentes a los anteriores y que mantenían su aspecto (tipostasis) desde el comienzo (tipogénesis) hasta su desaparición (tipolisis). El problema «se resolvió» invocando la escasez del registro fósil, pero aunque se puso toda la voluntad en la búsqueda de los «eslabones perdidos», éstos no se hallaron y el registro siguió mostrando tozudamente tipostasis prolongadas, así como discontinuidades entre diseños. Simpson (11) intentó una explicación diferente para las discontinuidades entre tipos, suponiendo una altísima tasa evolutiva en estirpes que hubieran sufrido reducciones drásticas en el tamaño de sus poblaciones; reconocía así la posibilidad de evolución rápida (evolución cuántica) debida a deriva genética, en poblaciones pequeñas.

El desarrollo de la Genética proporcionó una base material a los postulados de Darwin, mostrando que la herencia de los caracteres "residía» en genes y cromosomas. Se trataba de averiguar qué modificaciones (génicas o genómicas) serían las responsables de los cambios en los caracteres que determinarían la transformación de un linaje en otro, es decir, cuáles serían los determinantes (materia prima) del cambio evolutivo.

En torno a esta cuestión surgieron tempranamente dos tendencias: la de los que pensaban que en las macromutaciones, cuyos efectos proporcionaban cambios cualitativos y drásticos en el fenotipo, habría que buscar las claves para la génesis de nuevos diseños (Bateson, De Vries, Goldschmidt, etc.) y la de los que defendían que tales mutaciones sólo 
producían «monstruos» inviables que nunca podrían constituirse en especies o tipos nuevos; el origen de éstos habría que buscarlo en la suma de micromutaciones como mandaba el paradigma de cambio gradual.

Los «cualitativistas» perdieron la batalla frente a los «cuantitativistas» y la variación discontinua dejó prácticamente de ser materia de investigación mientras la genética de poblaciones se hacía dominante, desarrollándose en su seno modelos teóricos (Fisher, Haldane, Wright, Chetverikov, etc.) para el proceso evolutivo, entendido como variación cuantitativa de frecuencias alélicas en el seno de las poblaciones; la materia prima del cambio sería el material genético sometido a micromutaciones al azar y a recombinación y la selección natural debida al ambiente, la que dirige y canaliza la fijación o desaparición de unas u otras variantes; pronto se añadieron también, como fuentes de variación, hibridación y poliploidía que, si raras en animales, no lo son tanto en plantas.

Frente al concepto de cambio lento y gradual, Eldredge \& Gould (12) presentaron la "teoría de los equilibrios puntuados» (saltacionismo, abruptismo) en la que se resalta la existencia de periodos prolongados de tiempo en los que predomina la tipostasis de las estirpes, jalonados por periodos cortos y críticos, ricos en cambio evolutivo.

Frente a la consideración, demasiado simplista, de que es la variabilidad en el seno de las poblaciones el determinante fundamental de la evolución, se entiende ahora que hay multitud de fenómenos (a varios niveles) capaces de originar novedades evolutivas como pueden ser los de simbiosis, homeosis, incorporación de $\mathrm{ADN}$ foráneo, etc. No hay una traducción simple de genes a caracteres sino complejas relaciones jerarquizadas, reguladas y mediatizada (p. ej. por procesos homeóticos) que ponen en entredicho también la preponderancia del papel atribuido al azar; desde el nivel molecular, en adelante, no cualquier cambio es posible, manifestándose la importancia de la orientación endógena y de las restricciones impuestras por la estructura y la autoorganización.

Para Simpson (11) «el cambio genético determina el cambio morfológico y la tasa del primero se traduce en la tasa del segundo", sin embargo entendemos ahora que existe una estructura jerárquica de la variación, que ésta se produce en todos los niveles de la jerarquía biológica y que en todos debe ser estudiada en sus particularidades y en sus consecuencias. Cada uno de los niveles requiere de la información contenida en los anteriores pero no se puede explicar sólo como suma de sus componentes ya que, cada vez, aparecerán propiedades e información nuevas (emergentes) derivadas de la integración, cohesión, coordinación, regulación, comunicación... de sus partes, propiedades que no se hubieran po- 
dido predecir del estudio por separado de cada una de ellas. Así como la condición líquida del agua no se deduce automáticamente de la gaseosa del oxígeno y del hidrógeno, de las propiedades de las moléculas no podemos deducir todas las una célula (una célula es algo más que un saco de moléculas) y así sucesivamente a lo largo de la jerarquía biológica.

La consideración de que el conocimiento de la variación en el nivel molecular (o en cualquier otro) es bastante para comprender el proceso evolutivo en su conjunto, es reduccionista y la teoría Sintética lo es en su consideración del origen de la variación.

Frente a la competencia y la selección natural que «elegirá a los más aptos», como elementos canalizadores de la variabilidad natural, otros elementos, tales como la cooperación e integración de entidades, han de ser considerados. $\mathrm{Y}$ todo ello en los diferentes niveles de la jerarquía biológica (desde el molecular hasta el ecosistémico); sólo conociendo el modus operandi de la evolución en todos y cada uno de ellos podremos obtener tanto síntesis parciales como generales.

Gould (13) protesta de la hegemonia de la microevolución en el pensamiento neodarwinista, una síntesis reduccionista que necesita ser sustituida por el pluralismo y por el análisis de múltiples niveles de causas. En este mismo sentido postulan algunos autores (p. ej. Sandín (14) modelos de evolución debida a la integración de sistemas complejos autoorganizados en niveles de complejidad sucesivamente mayor, considerando la posibilidad de génesis de entidades nuevas y diferentes mediante integración de «cuantos» (sistemas ya complejos en sí mismos) que se asocian para formar un nuevo cuanto aún más complejo.

Repasaremos a continuación, someramente, lo que pueden decirnos algunos datos «de la botánica» sobre los temas mencionados.

1. Tempo (Cambio lento y gradual vs. rápido y abrupto): ¿qué dicen el registro fósil, los relojes moleculares y las filogenias «vegetales»?: Hace tan solo medio siglo no se tenía certeza de la existencia de vida en el Precámbrico; desde entonces hasta ahora las bases de datos del registro fósil no han dejado de crecer en paralelo con la discusión acerca de la completitud del mismo. Parece haber consenso sobre su suficiencia para la mayor parte de las estirpes, aunque aún con lagunas para otras $(15,16,17$, etc.); según Benton (18), globalmente, el registro está lo bastante completo como para leer en él directamente los avatares de la evolución en cada momento.

De tal lectura parece deducirse que la diversidad biológica no ha dejado de crecer aunque con tempo ralentizado en sus comienzos y acelerado en los últimos 600-500 $\mathrm{Ma}(18,19,20)$; también que este crecimiento se ha visto jalonado por crisis de extinciones masivas seguidas, cada vez, 
por nuevas explosiones evolutivas. La extinción de especies no se ha considerado normalmente como un elemento importante en el neodarwinismo siendo que, en palabras de Raup (21) «para un biólogo ignorar la extinción es como para un demógrafo olvidar la mortalidad».

Las grandes extinciones en masa conducen a importantes reestructuraciones en la biosfera, así tras un periodo transitorio de pobreza biótica, sobreviene la expansión de los clados sobrevivientes; éstos, que con frecuencia habían sido poco relevantes (cualitativa y cuantitativamente) en las biotas anteriores, protagonizarán las nuevas radiaciones evolutivas llamadas a ocupar (generar) los nuevos hábitats «liberados» en cada crisis. No puede predecirse a priori qué especies serán sobrevivientes y cuáles perecerán. Según Benton (18) hay poca evidencia de que la extinción se deba a selección, en el sentido defendido por Darwin.

Sobre estos temas cabe hacerse varias preguntas: ¿confirman los datos del registro fósil vegetal, y otras evidencias, los equilibrios puntuados? ¿qué es lo que determina que tras una crisis surjan súbitamente numerosas nuevas líneas filéticas? ¿qué cambios o reajustes se producen en sus genomas?.

Datos en el registro fósil: Los primeros habitantes del Planeta fueron de tipo procariótico (Bacteria), unicelulares o filamentos simples y muy variados estromatolitos (22) cuya morfología cambió poco durante los primeros c. $1000 \mathrm{Ma}$, entre hace c. 3800 y c. $2800 \mathrm{Ma}$ (23). Quizá las primeras cianobacterias surgieron hace c. $3500 \mathrm{Ma}(24)$ y con ellas la fotosíntesis oxigénica que acabaría por modificar la atmósfera (25, 26).

No se (re)conoce registro fósil de arquebacterias (Archaea) pero ciertas señales geoquímicas sugieren la posible existencia de estirpes metanógenas hace al menos $2800 \mathrm{Ma}$, momento que, si no de su origen, podría serlo de su expansión. Algún reloj molecular (27) obtiene el tiempo de divergencia entre Bacteria y Archaea en el intervalo de hace c. 4000-3000 Ma. Tampoco se conoce el momento de origen de los eucariontes (Eykarya) que algunos ubican hace c. $2700 \mathrm{Ma}$ (lípidos fósiles) y otros (28) hace c. $2000 \mathrm{Ma}$ (reloj molecular)

En torno a hace c. $2500 \mathrm{Ma}$ debió ser un periodo de cambios importantes en la biosfera en el que, aparte de la posible expansión de las Archaea, hubo una renovación de tipos bacterianos: cocoides de mayor tamaño, diversidad de filamentos septados y sifonales, formas inusuales muy diferentes de las modernas, etc., quizá en relación con el incremento de oxígeno atmosférico y además con la probable presencia de la estirpe eucariótica que para Knoll (29) podría haber sido aerobia desde el comienzo (por lo que sería también de este momento la incorporación 
endosimbiótica de la mitocondria, quizá en el origen mismo de los eucariontes).

Por su parte Belfort (30) (reloj molecular) ubica además en este periodo la incorporación (en alguna estirpe eucariótica de las recién originadas) de un nuevo pasajero intracelular: una cianobacteria (plasto primario). Tal estirpe, ancestral de algas rojas, verdes y glaucófitos, quedaría constituida como la primera eucariótica fotosíntetizadora; su rama hermana incluiría al ancestro común de Fungi+Animalia. Knoll (29) sin embargo ubica la adquisición de plasto primario en torno a hace c. $2000 \mathrm{Ma}, \mathrm{mo-}$ mento en que comenzaría un «big bang» de los eucariontes.

Una cifra anterior, c. $2200 \mathrm{Ma}$, es la que proporcionan algunos relojes moleculares (31) para la mentada explosión. Ésta debió suceder tras la caída de diversidad que sin duda determinó la intensa glaciación global datada en hace c. $2400 \mathrm{Ma}$ (23). Knoll (22) da cuenta de la recuperación renovada de la diversidad ya entre los 1900 y los $1600 \mathrm{Ma}$, con una variedad de estromatolitos (también los de modelo cónico) y de fósiles eucarióticos, entre ellos acritarcos sencillos, filamentos diversos y formas megascópicas, todos difícilmente adscribibles a los grupos alginos actuales; se reconocen de c. $1600 \mathrm{Ma}$ escamas compatibles con las de clorófitos unicelulares (micromónadas) pero muy distintas de las recientes y se detecta un incremento de tamaño en el conjunto eucariótico unicelular. Hace c. $1400 \mathrm{Ma}$ aparecen acritarcos esculturados (22) y escamas compatibles con las de las estirpes doradas (crisófitos) también diferentes de las actuales. Algún reloj molecular ubica en este momento el origen de las algas rojas aunque el primer fósil indiscutible de éstas es poco más reciente (c. 1300-1200 Ma) así como el de filamentos posiblemente referibles a algas verdes. Escalante \& Ayala (33) consideran que en este periodo (reloj molecular) surgieron los alveolados; más tarde se produciría una explosión evolutiva de sus clados mayores (básicamente ciliados y dinoflagelados).

En el intervalo de entre hace c. $1200-1000 \mathrm{Ma}$ sitúan algunos relojes moleculares la divergencia entre Fungi y Animalia, argumento que esgrime Pagel (34) para negar el big-bang animal del Cámbrico, sin tomar en cuenta que momento de tipogénesis y momento de explosión evolutiva son cosas diferentes y no necesariamente coincidentes en el tiempo: unos y otros pudieron ser elementos poco conspicuos al principio hasta su momento de diversificación y expansión. En este intervalo comienza la segunda gran explosión eucariótica (que debió serlo también bacteriana pues entre c. 1200-900 Ma se produce la mayor diversidad de estromatolitos); se reconoce una nueva renovación de acritarcos, algas rojas y verdes y una radiación diversificadora del conjunto pardo-dorado (35). Cabe 
señalar que, de las algas verdes unicelulares, hay escamas tipo Pyramimonas ya muy semejantes a las actuales.

Nuevamente, hace c. 900-800 Ma hubo una crisis de bacterias seguida de una modernización de las mismas. La diversidad eucariótica también parece renovarse: acritarcos muy diferentes de los anteriores, protista testados, escamas similares a las de crisófitos sinúridos y haptófitos cocolitofóridos aunque no referibles sin dudas a estos grupos (36); se ubica (reloj molecular) en este tiempo la divergencia de los apicomplejos desde sus ancestros dinoflagelados. Y ciertos fósiles de este periodo son interpretados por algunos autores como de metazoos. Con $800 \mathrm{Ma}$ se conocen fósiles de pseudofungi: oomicetes saprolegniaceos (37) y de hace c. $700 \mathrm{Ma}$ de verdaderos hongos quitridiomicetes. Entre hace $800-600 \mathrm{Ma}$ parece que hubo nuevas glaciaciones (23), tras las que florecieron las faunas Ediacaranas y las biotas de Burgess Shale.

A partir de este momento los tempos evolutivos se aceleran: estamos a las puertas de la radiación cámbrica (que también lo es bacteriana: hace c. $550 \mathrm{Ma}$ se aprecia otra renovación de formas que serán ya prácticamente iguales a las actuales); en cuanto a los eucariontes, aparecen nuevos acritarcos muy ornamentados, se renuevan las estirpes de algas verdes (p. ej., micromónadas nuevas y primeros fósiles codiáceos o dasycladáceos) y rojas (p. ej. Solenoporáceas), hay expansión de los grupos pardo-dorados cuyas escamas ya son similares a las de los crisófitos actuales aunque más grandes, los hongos quitridiomicetes invaden las aguas dulces, se originan los zigomicetes glomáceos (reloj molecular de Berbee \& Taylor (38) y radian los animales celomados.

Knoll (35) lo define como una espiral ecológica que continuará durante el Ordovícico con la incorporación de nuevos clados en el mar (especialmente animales aunque también de algas rojas y otras) pero sobre todo en los continentes con la aparición de las Planta: esporas en tétradas, «tubos» y cutículas nos hablan de una súbita diversidad de plantas prevasculares; acompañando a las primeras plantas aparecen también filamentos fúngicos septados no referibles exactamente a los grupos actuales sino al ancestro común de basidio y ascomicetes.

El Ordovíco acaba con una glaciación global y, como es habitual, extinciones masivas en tierra y mar. Tras ellas, el Silúrico conoce una nueva radiación modernizadora de animales marinos, algas verdes terrestres (p. ej. de Sycidiales y Trochiliscales entre las carofíceas) y plantas: la diversidad de cutículas y esporas es mayor que en el periodo anterior habiendo díadas, tétradas y mónadas triletas (indicadoras ya de flora vascular) muy diversas; cabe mentar a Dyadospora similar a las de hepáticas actuales (39) que indica el florecimiento de este clado. Y no se puede ob- 
viar la presencia, en el Silúrico superior, de Cooksonia, una planta con estomas y sistema conductor no lignificado, al modo de los hidromas de los musgos. En el silúrico superior ya están presentes las plantas vasculares lignificadas, al menos zosterófitos y sus descendientes licopodiófitos (40).

El Devónico es el periodo más espectacular en cuanto a la evolución de las plantas; en el inferior había una gran diversidad de hepáticas, musgoides (Sporogonites, Tortilicaulis, Steganotheca, Horneophyton, etc.) y de sus parientes cooksonioides (Uskiella, Hsüa, Yarravia, Aglaophyton, etc.), pero también de vasculares con lignina, como los riniodes (Rhynia, Renalia, Nothia, etc.) y los ya mencionados zosterófitos y licopodiófitos. Clásicamente se ha considerado que los zosterófitos derivarían de algún rinioide pero no se han hallado fósiles de este grupo anteriores al Devónico, y parece difícil que sus descendientes (y los descendientes de sus descendientes) sean anteriores a ellos, como sugiere la presencia de zosterófitos-licopodiófitos ya en el Silúrico superior; cabe pensar que el registro fósil de los rinioides más tempranos no ha sido encontrado o, alternativamente que hubo una estirpe anterior, derivada de cooksonioides, en la que se lignificó por vez primera el sistema conductor y que, de ella, derivarían tanto los rinioides como los zosterófitos, resultando ser grupos hermanos en vez de ancestro-descendiente. Unos y otros son afilos y con ramas dicótomas, apareciendo ya un tipo de folioma en los licopodiófitos (Drepanophycales, Protolepidodendrales).

Con la expansión de las plantas vinieron los primeros animales terrestres (arácnidos, miriápodos...) así como una nueva diversificación de hongos (38) que se patentiza no solo en la gran expansión de zigomicetes glomáceos sino también en la divergencia desde el común ancestro (reloj molecular) de los eumicetes (basio y ascomicetes). En el mar se aprecia la surgencia de nuevas algas verdes calcificadas y nuevas micromónadas con escamas ya referibles a las formas actuales.

Hacia el Devónico medio, pese a la caída de la mayoría de los cooksonioides, riniófitos y zosterófitos, la explosión fué aún mayor, con el origen de plantas aún afilas pero con ramificación alterna: los trimerófitos, quizá derivados de algún rinioide, y (prácticamente a la vez) de sus propios descendientes helechoides y progimnospermoides. Fué en este periodo cuando se constituyeron los primeros bosques (41) que albergaron a los primeros tetrápodos (anfibios tipo Ichtyostega). Se produjo también una expansión modernizadora de algas rojas macroscópicas, de verdes Coleochaetales y Charales, de hongos micorrícicos y líquenes, de hepáticas (como Pallavicinites, ya de aspecto moderno), etc. Descendientes de progimnospermas, surgieron en el Devónico superior, las primeras plantas con semilla y desde alguna línea helechoide (probablemente cladoxi- 
leana) se diferenciaron los primeros equisetófitos (Pseudoborniales, Sphenophyllales y Archaeocalamites).

El tránsito Devónico-Carbonífero vino nuevamente marcado por glaciaciones y declive en las biotas, desaparecieron los acritarcos (inmediatamente seguidos por una explosión dinoflagelada), se extinguieron también las carofíceas Sycidiales y Trochiliscales (tomando el relevo las modernas Charales), otras muchas algas verdes declinaron y, de la flora terrestre, desaparecieron los últimos restos de las estirpes más antiguas, incluidos los trimerófitos y algunos helechoides (cladoxilidos, iridopteridos) así como la mayoría de progimnospermas.

El Carbonífero es de nuevo momento de tipogénesis: además de la dinoflagelada, el reloj molecular ubica el origen de las diatomeas, el registro fósil incorpora a las algas verdes desmidiaceas (iguales a las actuales) en las aguas dulces, y también cocolitos (que quizá correspondan a haptófitos) y nuevas algas rojas calcificadas (ancestrales de corallinoides); en el inferior hay basidiomicetes (royas) de poro simple y en el superior los primeros ascomicetes. Se detectan nuevas hepáticas (como las actuales Pallavicinia, Metzgeria o Fossombronia a la vez que otras no referibles a formas actuales) y musgos diversos (entre ellos Polytrichum).

De la flora euvascular, surgen los licopodiófitos Lycopodiales (como los actuales), Lepidodendrales (algunos gigantescos) y Selaginellales; se aprecia una extensión de helechoides stauroptéridos y zygoptéridos y el máximo desarrollo de equisetófitos Sphenophyllales y Archaeocalamites pero también el origen de Equisetales y Calamitales.

Los verdaderos helechos (p. ej. Marattiales) surgen en el Carbonífero medio así como las familias Filicales más plesiotípicas (botryopteridáceas, anachoropteridáceas, tedeleaceas) que durarán hasta el Pérmico. Quedan progimnospermas residuales (Protopytiales) y radian las pteridospermas (Calamopityales, Buteoxilonales, Lyginopteridales, Medullosales, Callistophytales). Hacia el Carbonífero medio se originan las primeras cícadas (Spermopteris, Taeniopteris) y los coniferoides (cordaitidos). Verdaderas coníferas (utrechtiáceas, emporiáceas...) se presentan en el Carbonífero superior.

Se reconstruye este periodo como de buen clima, cálido y húmedo, al menos en el hemisferio norte, lo que posibilitó el establecimiento de bosques complejos en torno a grandes áreas pantanosas, en valles y colinas, donde medraron diversos artrópodos, entre ellos los primeros insectos así como anfibios modernizados y los primeros reptiles; insectos alados aparecen en el Carbonífero superior.

A finales del Carbonífero sucedió un enfriamiento paulatino del clima, con desecación de amplias áreas pantanosas, lo que determinó una crisis 
en la vegetación: se extinguieron los licopodiofitos plesiotípicos, helechoides, la mayoría de las pteridospermas y la mayoría de los cordaitidos.

Durante el Pérmico continuó el enfriamiento, con varios pulsos, y la sequía, determinando una gran pobreza florística y faunística, a la que seguirá una explosión y expansión de estirpes resistentes, que acabarán dominando en todo el mesozoico (42): matorrales de helechos (osmundáceas y quizá schizaeaceas y gleicheniáceas), pteridospermas xerófitas (glossopteridales que dominarán en el Pérmico tardío, peltaspermales), ginkgófitos en los mejores ambientes, cícadas renovadas (Phasmatocycas, Archaeocycas) y también nuevas familias coníferas (ferugliocladáceas, buriadiáceas, majonicáceas, ullmanniáceas...). Unos pocos cordaitidos quedan aún y también habrá musgos (varios ordenes y familias modernas) además de los primeros esfagnos (Protosphagnum). De los equisetófitos habrá aún Sphenophyllales, Equisetales y Calamitales pero ya formas de escaso porte y de los licopodiófitos irán desapareciendo los gigantes y, los menores, pasarán a ser elementos poco importantes en las biotas siguientes. Igual que la vegetación cambia drásticamente, lo hace la fauna, desarrollándose en este periodo tras la pobreza inicial, una muy rica reptiliana y de terápsidos.

La crisis Permo-Trías (se dice que debida a varios pulsos de frío intenso muy seguidos) se considera, si no la mayor, una de las más graves sufridas por la biosfera, con la extinción del 80-95\% de las especies, 50$70 \%$ de los géneros y $50 \%$ de las familias vegetales. Desaparecieron los últimos restos de «aspecto» paleozoico de suerte que el Triásico comienza prácticamente con un desierto ecológico: floras y faunas generalizadas y paupérrimas como la casi monoespecífica «flora Dicroidium», una pteridosperma, que se instaló en Gondwana.

En un nuevo periodo de tipogénesis, surgen nuevos licófitos (Pleuromeiales e Isoetales) ahora de escaso porte, nuevos equisetófitos calamitales (Neocalamites...) también pequeños, nuevos helechos (mattoniáceas y gleicheniáceas seguras) y pteridospermas Coristospermales (como el mencionado Dicroidium) y Caytoniales ya en el Pérmico superior.

Las cícadas (Bjuvia, Leptocycas...) se renuevan en el Trías superior en un proceso de anagénesis rápida, así como las coníferas con el origen de nuevas familias, entre ellas varias de las modernas (palissyáceas, cheirolepidiáceas, pináceas, podocarpáceas, araucariáceas, taxodiáceas). Es también momento de tipogénesis de cicadeoides o Bennetitales (Wielandiella y otras) y de gnetófitos (Maculostrobus, Dinophyton, polen tipo Ephedra y tipo Welwitschia, formas muy diferentes de las actuales) ambas estirpes (Bennetitales y Gnetales) aún poco importantes. Algunos relojes moleculares indican también el origen de las angiospermas. 
Se produce en paralelo una radiación de basidiomicetes y ascomicetes que empiezan a mostrar carpóforos complejos. Hay además una renovación de insectos (coleópteros, himenópteros), una radiación renovadora de anfibios, dinosaurios, tortugas, cocodrilos... así como, en los mares, de peces elasmobranquios y osteictios; se reconocen dinoflagelados goniaulacoides y peridinioides pero con escasa diversidad, primeras algas rojas Gigartinales y recuperación renovada de algas verdes calcificadas. Hacia el Trías medio ya se han recuperado las biotas pero el paso al Jurásico se define por una extinción faunal masiva, atribuida (estudios geoquímicos) a un efecto invernadero, en el que la concentración de $\mathrm{CO}_{2}$ llegó a ser cuatro veces superior a la actual (43).

En el Jurásico se originan los basidiomicetes con doliporos, nuevas hepáticas (algunos géneros modernos como Riccia) y, de entre los musgos, surge el género Sphagnum; también hay una renovación de helechos (dicksoniáceas, cyateáceas, dennstaedtioides, pteridoides, blechnoides, dryopteridoides) originándose las familias (o plexos) actuales que radiarán en el Cretácico. Las pteridospermas Caytoniales continúan su diversificación en el hemisferio norte y, de las coníferas, hay que anotar el origen de las taxáceas (Paleotaxus) y cefalotaxáceas. Todo el Jurásico (y Cretácico inferior) es el momento álgido de ginkgófitos y cícadas aunque éstas renovadas en los géneros modernos; lo es también de extensión de coníferas (muchas familias renuevan sus géneros) y también son importantes las Bennetitales renovadas (Weltrichia, Williamsonia, Cycadeoidea...).

Es también el momento de tipogénesis de los mamíferos ovíparos (44) y de los anfibios anuros. Del Jurásico medio se conocen los antófitos Pentoxylales (a los que se supone parientes de gnetofitos, cicadeoides y angiospermas) y el primer fósil angiospérmico (Archaefructus). El Jurásico superior conoce el origen de lagartos y aves, radiación de cocodrilos y es el momento álgido de los dinosaurios saurópodos; también se produce una extensión de dípteros y lepidópteros y ya son muchas las familias de insectos constituídas por aquél tiempo como las modernas. En los mares se expanden los dinoflagelados (génesis de dinofisioides y cetariáceos y explosión de goniaulacoides y peridinoides). Se aprecia (en el registro fósil, confirmado por datos moleculares) una explosión de los grupos del clado pardo-dorado, del cocolitofórido (=haptófitos) y es momento álgido para las algas rojas calcificadas (como solenoporáceas).

La crisis del fin del Jurásico parece relacionada con una nueva ola de frío que determinó el declive de los dinoflagelados y otros protista, algas rojas nemaliales, algas verdes charales y, entre las plantas, la caída de los últimos licófitos pleuromeiales. 


\section{Botánica y Evolución}

En el Cretácico inferior se inicia un nuevo calentamiento y con él se expanden extraordinariamente nuevos dinoflagelados, registrándose los primeros de agua dulce; parece momento de diversificación de crisofíceas y diatomeas marinas, y también se renuevan los cocolitofóridos; momento de recuperación de Charales (clavatoráceas) y de génesis, en las algas rojas, de muchos de los ordenes que han llegado a nuestros días. En los continentes radian explosivamente los basidiomicetes (ectomicorrizas) y los ascomictes.

Es momento de extensión de helechos y origen de algunos nuevos como asplenioides y polipodioides, de acmé de los ginkgófitos, y de expansión de Isoetales (tras la caída de Pleuromeiales). Las coníferas son muy abundantes, diferenciándose el género Pinus (45). Aún son importantes las pteridospermas Czekanovskiales y Caytoniales o las cícadas, produciéndose el acmé de los cicadeoides (=Bennetitales) y el origen de nuevos gnetófitos (Drewria, Eoantha) que también ganan su máxima distribución y diversidad. Las angiospermas son ya muy diversas y continúan en rapidísima radiación Barremiense-Aptiense $(46,47)$. El registro fósil indica la presencia de estirpes clorantoides, tipogénesis de monocotiledóneas y de euangiospermas (las que tienen polen tricolpado). Paralelamente diversifican lagartos, serpientes, aves y terios.

En el Cretácico medio el calor es máximo lo que, junto a los fenómenos de vulcanismo y los derivados de la orogenia alpina, determinó una crisis aunque no global ni masiva. De las algas verdes carofíceas se extinguieron las clavatoráceas (sólo quedó la familia Characeae) y también los helechos arcaicos (el grupo protagonizó inmediatamente después una radiación, con la génesis de la mayoría de las familias modernas). Desaparecieron las cheirolepidiáceas (pero no otras coníferas) y fué la crisis definitiva para las Bennetitales y para los dinosaurios enormes. Como contrapartida no sólo hubo la ya comentada radiación mayor de los helechos modernos, en la que hay que contar además el origen de los hidroptéridos marsileales, sino también una nueva explosión de angiospermas: magnólidas herbáceas (clorantoides) y arbóreas (Magnoliales y Laurales), nuevas monocotiledóneas y ranuncúlidas (Ranunculales), nuevas hamamélidas platanáceas y Trochodendrales, pero sobre todo una expansión de rósidas-dilénidas (Myricales, Juglandales, Urticales, Hippuridales, Celastrales, Ericales).

En paralelo se produce una renovación de insectos (p. ej. con la génesis de apoideos y vespoideos), el origen de los mamíferos vivíparos y una radiación de aves. En el mar se reconoce la tipogénesis de los silicoflagelados y la expansión de nuevas algas verdes sifonales y también de clorofíceas que ya se corresponden con taxones actuales. 
En el Cretácico superior ya se aprecia localmente la dominancia angiospérmica así como la radiación de Fagales, Betulales, Euphorbiales, Myrtales y en el Maastrichtiense, Caryophyllales, Ebenales, Malvales, Fabales, Geraniales, Santalales, Proteales, Arecales, Pandanales. En paralelo desaparecen las pteridospermas Caytoniales y comienza el declive de los ginkgófitos hasta su extinción virtual en el Terciario. Las coníferas siguen siendo importantes, con explosión de especies de pinos y la génesis de Cuppresaceas, Cedrus y quizá Larix. En los mares es el acmé de silicoflagelados y cocolitofóridos y en las aguas dulces diversifican las algas verdes caráceas y surgen las diatomeas pennales.

La banda Creta-Terciario se determina por una crisis aguda, con regresiones marinas y enfriamiento de las aguas, plasmada en la desaparición desastrosa del plancton (aunque las diatomeas pasaron indemnes). En los continentes hubo extinciones pero sobre todo grandes migraciones de floras (p. ej. de helechos); los gnetófitos sufrieron severamente, aunque la crisis no fue bastante para detener el continuo avance angiospérmico. Se acabaron de extinguir los dinosaurios no avianos y hubo también desapariciones en otros grupos faunales aunque, como en la flora, predominaron las grandes migraciones.

En el Terciario (Paleoceno) se incorporan nuevos ordenes o familias (p. ej. papilionáceas) de angiospermas: Hamamelidales, Eucommiales, Casuarinales, Polygonales, Rutales, Polygalales, Cornales, Gentianales, Restionales, Poales, Thyphales, mientras en el mar se expanden nuevos dinoflagelados, se produce una explosión de algas pardas, una recuperación de cocolitofóridos, con la tipogénesis de formas más grandes, nuevas algas verdes sifonales y, en las aguas continentales el origen del moderno género Chara.

$\mathrm{Al}$ final de Paleoceno sufrieron una nueva crisis las estirpes planctónicas (dinoflagelados, diatomeas marinas, silicoflagelados, foraminiferos, radiolarios...) y también las algas rojas calcificadas plesiotípicas (que vendrán a ser sustituidas por las modernas corallináceas) tras la cual se produjo la consiguiente recuperación-renovación, ya en el Eoceno, de los grupos mencionados. En las aguas dulces se origina el género Spirogyra con las características que han llegado a nuestros días. También renuevan sus géneros las hepáticas y se originan nuevos ordenes angiospérmicos: Theales, Thymeliales, Nepenthales, Polemiales, Dipsacales, Cyperales, Liliales. Termina el periodo con una nueva crisis particularmente aguda en los mares que afectó sobre todo a las especies planctónicas.

Ordenes angiospérmicos con tipogénesis en el Oligoceno parecen ser, por ejemplo: Nelumbonales, Violales, Cucurbitales, Salicales, Rosales, Rhamnales, Oleales, Eleagnales, Campanulales, Asterales. Se reconoce 
en los mares, una nueva explosión de algas pardas con la tipogénesis de los ordenes actuales. $\mathrm{Y}$, al final del periodo una nueva crisis para el plancton.

El Mioceno vino cálido, con el desarrollo de estepas y desiertos, aquellas formadas por la extensión de plantas especialistas $\mathrm{C}_{4}$ y éstos colonizados por familias surgentes que desarrollan reservorios de agua en su soma (cactáceas, crasuláceas). Los nuevos ordenes de angisopermas que se originan en este periodo son: Lamiales, Plumbaginales, Dilleniales, Capparales, Primulales, Alismatales, Najadales, Arales. Parece también el momento de génesis de los ecosistemas de corte moderno cuya vegetación ya está constituida prácticamente como la reciente. En el mar se renuevan y expanden las diatomeas centrales; es momento de acmé para los silicoflagelados y de tipogénesis de las algas pardas laminariales y rojas florideofíceas. Sin embargo sigue disminuyendo la diversidad de los cocolitofóridos que no consiguieron recuperarse de la crisis anterior.

Del último periodo, Plio-Pleistoceno, cabe reseñar los efectos de las glaciaciones que provocaron, más que nada, grandes migraciones de floras y faunas aunque también trajeron el declive de algunas estirpes, entre ellas las cícadas en tierra o, en el mar, los silicoflagelados.

Con más incertidumbres sobre los tiempos más remotos y más certezas sobre los recientes, globalmente, el registro fósil «vegetal» proporciona escenarios de evolución que apuntan hacia equilibrios puntuados: surgencias explosivas de linajes, tipogénesis súbitas imposibles de obtener mediante cambios lentos acumulados, largas tipostasis, crisis y caidas de la diversidad sucedidas cada vez por nuevas explosiones renovadoras de estirpes y biotas. Llama la atención la rapidez con que se originan, en el Devónico y en sólo c. $50 \mathrm{Ma}$, prácticamente todos los tipos mayores de Planta, así como el hecho de que, en cada ocasión, las líneas descendientes surjan casi a la vez que sus antepasados, derivadas sin duda de las ramas más basales de aquellos.

Las filogenias moleculares parecen contar la misma historia, resolviéndose en radiaciones explosivas de linajes mayores (y lo mismo dentro de cada linaje de menor rango). En muchas ocasiones el orden de aparición de las estirpes de un mismo clado no es fácil de establecer (colapsándose las ramas en multifurcaciones) debido a la proximidad de los eventos cladogenéticos. Esto es lo que aprecia Pace (48) cuando expresa que la diversidad bacteriana parece haber nacido básicamente en una radiación explosiva de linajes; o lo que se deduce de la topología de tantos cladogramas como por ejemplo, de algas pardo-doradas y afines (49), algas rojas florideofíceas (50), helechos (51) o angiospermas (52). 


\section{Margarita Moreno}

\section{Revisando las fuentes de variación: entre la permanencia y el cambio}

La materia viva, mediante los procesos replicativos lo que «pretende» es permanecer (producir entidades iguales a las parentales) y, generalmente, lo consigue. En el paradigma darwinista, mediante cambio gradual, una especie «es» a la vez que continuamente «está dejando de ser», lo que resulta contradictorio con la permanencia (estasis) que muestra el registro fósil; alternativamente, Carson (53) propone que la especie «es» (lo que es y como es, mientras dura) porque posee un sistema o programa genético con una parte cerrada, refractaria al cambio (base de su permanencia) a la vez que otra más abierta, que admite ciertas modificaciones; éstas son irrelevantes para la condición de especie (que no deja de ser ella misma) pero le confieren una variabilidad que quizá proporciona ajustes (adaptaciones) locales. Sin embargo, los cambios en la parte cerrada del programa genético son los que pueden determinar modificaciones cualitativas y originar nuevas especies (o tipos mayores). Tales cambios han de ser raros en general, aunque parece que se desatan en situaciones de crisis, resultando en las explosiones evolutivas que suceden a las grandes extinciones.

Entonces ¿cuáles son las fuentes de variación a lo largo de la jerarquía biológica y que consecuencias pueden llegar a tener?, ¿se ajustan a los postulados neodarwinistas?, ¿cómo se puede modificar «esa parte cerrada» del programa genético específico?.

2a. Puede haber variación en el ADN, sea este codificador o no, en su secuencia (sustituciones de nucleótidos, insercionęs-deleciones, etc.), en su ubicación (transposiciones) o en su número (multiplicaciones de secuencia). La asunción de que la variación génica se produce al azar no parece confirmarse: la probabilidad de cambio no es la misma para cualquier nucleótido, ni para cualquier posición en el codón, las sustituciones sinónimas son frecuentes pero las no sinónimas son raras, hay fragmentos de $\mathrm{ADN}$ más proclives que otros a incorporar o a perder secuencias (in-del). Más que azar parece haber reglas: en ciertas secuencias o regiones el cambio está prohibido, reglas que hay que descubrir y precisar. En Planta los genes propiamente dichos se permiten escasa variación pero sucede lo contrario en las regiones espaciadoras.

El comportamiento de un gen puede modificarse según el lugar que ocupe en el cromosoma, las secuencias que lo flanqueen, etc. No sólo las mutaciones en su $\mathrm{ADN}$ provocan variación sino también la relación-coordinación-integración de unas secuencias (codificadoras o no) con otras. Ahora se está concediendo al ADN repetitivo toda la importancia que se 
le hurtó (tildándolo de "chatarra, parásito o egoísta») ante la evidencia de su participación en múltiples procesos vitales y de su papel como factor de evolución.

De entre las angiospermas, parece abundante en gramíneas y escaso en Arabidopsis, pero los datos son aún pocos y no es posible sacar conclusiones de valor general; no obstante, se sabe que buena parte del mismo es de origen viral y, con frecuencia, móvil: hasta el $70 \%$ del genoma de Hordeum vulgare es ADN móvil y sus cambios de lugar (alterando la expresión génica) provocan cambios en el fenotipo (54). Parece que los transposones son muy comunes en las plantas, que cambian con rapidez y que «se mueven» en situaciones de estrés ambiental, lo que, en palabras de Clegg (55), nos conduce a un «poco confortable lamarckismo».

Todos estos procesos, aún poco explorados, son algo más que los meros cambios en las frecuencias alélicas en el marco de la población, y abren una puerta a la posibilidad de modificación rápida en tiempos de crisis.

2b. Puede haber variación en los cromosomas: no son raras pérdidas o ganancias de genes, áreas de recombinación, fisiones y fusiones, translocaciones, inversiones y multiplicaciones. Con frecuencia estos fenómenos tampoco dependen del azar, por ejemplo, las áreas de recombinación no son cualesquiera: en Planta las regiones aledañas a los centrómeros (plagadas de genes) presentan recombinación intensa, mientras ocurre lo contrario en la región organizadora del nucleolo (56). La disposición de los genes también parece seguir reglas precisas, al menos para aquellos que actúan coordinadamente que aparecen siempre ligados e inseparables (operones bacterianos, genes Hox, tandem de la familia de genes $\mathrm{ADNr}$ o conjunto de genes que codifican las globinas, etc.), igual comportamiento muestran los (super)genes que controlan la heterostilia en Prímula o el tipo sexual en Chlamydomonas. De nuevo aparecen fenómenos de integración poco explorados.

Fuentes de variación cromosómica son también los fenómenos de hibridación y poliploidía, raros en animales pero menos en plantas donde pueden ir asociados de manera que, tras un cruzamiento hibridógeno, se restaura la viabilidad meiótica mediante duplicación cromosómica. En otras ocasiones se evita la esterilidad híbrida mediante la eliminación de uno de los genomas parentales (57). Recientemente se ha demostrado que la hibridación en angiospremas no es tan ubicua como se pensaba y, sobre todo, que no se distribuye al azar en la jerarquía taxonómica (58) sino que se concentra en ciertas familias y ciertos géneros, generalmente de plantas perennes.

Son comunes las redisposiciones (p. ej. translocaciones) en los genomas híbridos (59) quedando sus cromosomas como verdaderos mosaicos 
de regiones que contienen genes de ambos progenitores (60). Tales translocaciones no parece que se produzcan al azar sino de manera precisa y regulada: Song \& al. (61) dan noticia de la génesis de translocaciones idénticas en los híbridos artificiales de Brassica rapa x B. nigra y $B$. rapa $\mathrm{x} B$. oleracea en los que, al parecer, el genoma materno controla al conjunto del genoma.

Se suponía que la poliploidía sería favorecida por la selección ya que la repetición de genes proporcionaría mayor cantidad de productos, enmascararía las mutaciones deletéreas y dotaría de altos niveles de heterocigosis (con su correspondiente variedad de isozimas); también se dice que los poliploides sufren menos depresión por autocruzamiento, lo que parece cierto en helechos pero no en angiospermas, todo ello se consideraba causa de su mayor vigor, agresividad y valencia ecológica. Sin embargo, estudiados los valores de isozimas en helechos poliploides se encontró que eran semejantes a los de los diploides y, en angiospermas, los poliploides de cada género no presentan una distribución geográfica más amplia que la de sus parentales, lo que pone en entredicho también su presunta mayor valencia ecológica (57).

También hay que explorar más las consecuencias de la repetición de genes pues, en ocasiones, proporciona efectos sorprendentes; así, por ejemplo, si en Petunia se añaden copias de ciertos genes a fin de obtener una pigmentación más intensa, no se gana el efecto deseado sino que el centro del pétalo queda blanco; ello se debe a que algunos genes (en Planta y Animalia al menos) en dosis extra tienen efectos sobre la expresión de otros (los silencian). Galitski \& al. (62) también comprueban en Fungi (Saccharomyces) que la expresión génica varía según el nivel de ploidía: unos genes se inducen y otros se silencian. Poliploidía e hibridación son casi las únicas fuentes de variación súbita que reconoce el neodarwinismo aunque resulta evidente que aún abundan las incógnitas sobre su condición.

2c. Puede haber variación en los procesos de desarrollo y morfogénesis: Aún entendemos escasamente los mecanismos que subtienden la aparición de las formas biológicas (63) y sólo recientemente se estan comenzando a desentrañar algunos de ellos; lejos de la idea simplista de una relación directa "genotipo-fenotipo» lo que hay es una relación muy regulada y mediatizada por los procesos homeóticos. La forma biológica depende de la acción coordinada de ciertos genes. Los estructurales especifican productos y los reguladores especifican la actividad o paro de los anteriores en los lugares y tiempos adecuados; esto es lo que permite obtener distintos tipos celulares, tejidos y órganos. En los años 90 se ha comprobado que la morfogénesis es un fenómeno universal de la vida (au- 
toorganización en un nivel superior al génico-genético), con un orden intrínseco e inherente a la propia mecánica de la morfogénesis.

En el campo de la botánica son notables las observaciones de Stebbins, ya desde los años 50, sobre la relación positiva entre tamaño del primordio y de la flor (y de su cantidad de piezas), sobre el número de células iniciales necesarias para producir un primordio, sobre el tiempo en que las células iniciales retienen su particular capacidad de diferenciación, sobre las tendencias repetidas en angiospermas (ganancia o reducción de piezas, soldadura de partes, zigomorfía...), sobre su capacidad para la reversión o sobre el papel de determinados metabolitos en la formación de paredes celulares y su relación con la forma celular y organísmica.

En otro estilo (mediante simulaciones numéricas) también Niklas, desde los años 70, ha explorado la cuestión de forma y diseño y la relación recíproca de estructura y bioquímica (límites impuestos por los requerimientos mecánicos tanto como por los materiales de construcción disponibles). Cada diseño óptimo, apunta el autor, representa una condición estable pero puede perderse la estabilidad mediante perturbaciones producidas dentro del sistema (pérdida de coherencia interna) o fuera de él (estrés ambiental), y ello obligará (si no sobreviene la extinción de la forma) a un cambio que proporcione un nuevo diseño óptimo. Concluye así, por ejemplo, que un incremento de tamaño en las plantas pioneras terrestres (taloides dorsiventrales), manteniendo la relación superficie / volumen, sólo pudo alcanzarse mediante elaboración de formas lobuladas (como son las hepáticas) y que el cambio del modelo dorsiventral al erguido requiere de la formación de estructuras resistentes en la periferia de los ejes (antes que en el interior de los mismos) de manera que los cortex fueron los primeros elementos de sostén, antes de la aparición de las traqueidas lignificadas, lo que se cumple en el registro fósil.

Sabemos aún muy poco de morfogénesis en plantas. Éstas (como sus ancestros carofíticos) tienen crecimiento apical y órganos sexuales multicelulares pero desarrollan dos generaciones: gametofítica y esporofítica, una y otra con tejidos bien diferenciados.

Las áreas nodales en Chara y algunas especies de Coleochaete (grupos hermanos de Planta) son parenquimatosas y su crecimiento es marginal como en los meristemos de las plantas (64); las células meristemáticas (embrionarias) son muy plásticas y muchas diferencias de forma se deben a dónde y cuándo actúa (o se suprime) la proliferación celular (65, 66) que, a su vez, está controlada por hormonas (auxinas, etileno, hidroxiprolinas...). Stebbins (67) informa de hepáticas a las que se aplican inhibidores de la hidroxilación de las prolinas que se desarrollan con feno- 
tipos «más primitivos», igualmente mutaciones en los genes para las glicoproteinas asociadas a las paredes celulares pueden promover diversidad de formas.

De las diferencias entre gametófitos (n) y esporófitos (2n) se pensó que podrían tener su base en el nivel ploídico pero existen gametófitos $2 \mathrm{n}$ (a partir de esporas que no han sufrido meiosis) y esporófitos $\mathrm{n}$ (a partir de gametos sin fecundar); se sabe de diferencias (citológicas) entre esporas y gametos (más o menos ribosomas, desarrollo del sistema de endomembranas, etc.) pero apenas se alcanza a comprender su significado biológico o su papel en la morfogénesis. El estudio de estos temas es una asignatura pendiente. Algo más se ha avanzado en el que es, por el momento, el tema estrella: la morfogénesis floral.

En los años 80 se descubrieron (en genes embrionarios responsables de la identidad de los órganos animales) las secuencias homeobox. Posteriormente se comprobó que muchas de ellas tenían homólogas en genes de Fungi y Planta y también de Bacteria (las habrá también de Protista). La función de los genes con esta secuencia (genes Hox) es la de regular a otros genes. En Planta (Antirrhinum y Arabidopsis) se detectó la presencia de una segunda familia multigénica (genes MADS-box, también con homólogos al menos en Fungi y Animalia) con la misma capacidad; los genes MADS-box están involucrados en la identidad de los órganos florales aunque no son los únicos que intervienen en la producción de inflorescencias y flores.

Las plantas tienen un meristemo apical para el crecimiento caulino que genera, en su periferia, primordios foliares; en la axila de la hoja se forma un meristemo secundario para producir nuevas ramas (o yemas). Existen genes que determinan la transición entre ramas vegetativas y ramas floríferas (inflorescencias) así como entre inflorescencias indeterminadas y determinadas o entre hojas y flores y lo hacen mediante juegos de expresión/represión. La expresión de algunos está mediatizada por señales ambientales y endógenas $(68,69)$. Se conocen genes (en Arabidopsis) cuyos productos aumentan o disminuyen según el ciclo día/noche, que regulan la expresión de otro gen (para criptocromos) involucrado en los ritmos circadianos (Animalia y Planta); los criptocromos son flavoproteinas que absorben la luz azul y ésta es necesaria para inducir la floración $(70,71)$. Acerca del tiempo de floración (temprano vs. tardío), Weigel (69) da noticia de c. 20 genes (c. 12 relacionados con hormonas) involucrados, algunos de los cuales dependen de la luz para su expresión.

Obteniendo inflorescencias: la presencia del gen CEN de Antirrhinum (= TFL 1 de Arabidopsis) determina que el meristemo crezca como rama pero la expresión del gen FLO de Antirrhinum (= LFY de Arabi- 
dopsis) lo inhibe y el tejido meristemático formará una flor $(72,73,74)$. Mutantes de CEN (inactivación) también acabarán las ramas en flor (75). A su vez CEN reprime a FLO y del juego en diferentes lugares y momentos de la expresión de uno u otro se obtienen las diferentes arquitecturas de las inflorescencias (76), resultando determinadas si en el meristemo apical actúa FLO o indeterminadas si sólo lo hace en los primordios laterales.

El cambio de un modelo de inflorescencia a otro se ha producido (y revertido) varias veces en la evolución de las estirpes angiospermas. Por otra parte, la inflorescencia será bracteada o ebracteada según se exprese o no FLO en el primordio bracteal. FLO se puede expresar en brácteas, sépalos y péıalos (induciendo la expresión de AP1) pero no en estambres o carpelos $(76,77)$. Posteriormente se concluiría que para la formación de inflorescencias con flores se requiere la acción coordinada de al menos cinco genes: FLO, AP1, UFO, CAL y AP2 (algunos de los cuales son redundantes).

Elaborando flores: Una vez ganada la identidad floral por un meristemo se inicia el desarrollo de la flor: nuevos genes (homeóticos) y su juego de expresión o silencio, conferirán identidad a los verticilos (unidades merísticas); si uno de ellos se expresa en un lugar incorrecto, se producirán órganos normales en una posición anormal (78) al modo en que salen patas en el lugar de las antenas en Drosophila. Lacandonia schismatica representa este caso, con los estambres en el interior, rodeados de carpelos; esta mutación no es adaptativa (es planta cleistógama y no supone ventaja alguna para su fertilización) por lo que el rasgo debió fijarse sin concurso de la selección natural.

Según parece los genes involucrados en el desarrollo de los dos primeros verticilos y los necesarios para formar el cuarto (carpelos) se inhiben mutuamente. De esta manera el lugar (verticilo) en que aparecerán los primordios de cada tipo de órgano está muy controlado genéticamente; no tanto el número de órganos resultantes pues parecen fáciles incrementos o decrementos de pétalos, estambres o carpelos, a juzgar por las numerosas veces que han sucedido a lo largo de la evolución de las familias angiospérmicas.

\section{Cascada de genes para la especificación de órganos florales}

El estudio de los fenotipos aberrantes determinados por mutaciones de los genes homeóticos (de tipo A: carpelos en vez de sépalos y estambres en lugar de pétalos, de tipo B: sépalos en vez de pétalos y carpelos 
en vez de estambres, de tipo C: pétalos en vez de estambres y sépalos en lugar de carpelos) condujo (76) a suponer un modelo en cascada (orden de expresión) de genes que sería el responsable de la identidad de los órganos singulares y de su desarrollo en el verticilo correcto. Comenzarían expresándose los genes de clase A y se definirían sépalos; a estos se añadirían los de clase $\mathrm{B}$ y juntos, formarían pétalos; el silencio de los $\mathrm{A}$ y la expresión de los $\mathrm{B}+\mathrm{C}$ determinaría estambres y los de clase $\mathrm{C}$ en solitario especificarían carpelos (fig. 1).

Los años 90 fueron fructíferos en la localización y estudio de las funciones de los genes de la «cascada $\mathbf{A B C}$ » que pronto se vería ampliada con genes de clase D para especificar óvulos. Se identificaron los genes AP1 y AP2 como de clase A; los parálogos AP3 y PI de clase B; AG de clase $\mathrm{C}$ y BELL y SUP de clase D. Ya se ha dicho que los genes AP y PI (primeros verticilos) inactivan a AG (cuarto verticilo) y viceversa, pero también BELL silencia a AG (en el momento de la formación de óvulos) y CURLY LEAF al principio del desarrollo floral para permitir la expresión de los genes de clase A y B. Por su parte SUP reprime a AP3 en el centro de la flor temprana pero le deja actuar en la tardía ya que se requiere (además de BELL y el propio SUP) en el desarrollo ovular.

Se pensaba que la secuencia ritualizada (en cascada) de los genes $\mathrm{ABC}$ bastaría para determinar flores y que su silencio en un meristemo indiferenciado permitiría el desarrollo de hoja (en vez de flor) sin embargo, la presencia de los genes $\mathrm{ABC}$ también en el cuerpo vegetativo de la planta, obligó a pensar que, para el desarrollo floral, debían intervenir aún más genes. Pelaz \& al. (79) añadieron una nueva clase de genes MADS-box a la cascada (clase E: genes SEP) cuya pérdida de función determina que todos los órganos florales se asemejen a sépalos; éstos no se expresarían en hojas $\mathrm{y}$, junto con los $\mathrm{ABC}$, especificarían la identidad de la flor y de sus órganos: $\mathrm{A}+\mathrm{B}+\mathrm{E}$ para pétalos, $\mathrm{B}+\mathrm{C}+\mathrm{E}$ para estambres $\mathrm{y}$ $\mathrm{C}+\mathrm{E}$ para carpelos.

Theißen \& Saedler (80) analizaron la filogenia de la familia de genes MADS-box encontrando que (duplicaciones aparte) se ha diversificado en tres clados: el primero formado por los genes de clase B (AP3, PI), el segundo por los de clase C y D (AG y los especificadores de óvulos) y el tercero por los de clase A (AP1, AP2) más los de clase E (SEP1, SEP2, SEP3). Los mismos autores proporcionan un modelo (que denominan «del cuarteto») como base molecular para la cascada. Se basan en los descubrimientos de Egea-Cortines \& al. (81) sobre el modo en que las proteinas MADS-box interactúan y ligan el $\mathrm{ADN}$ : normalmente como dímeros pero algunas (en Antirrhinum) forman complejos multiméricos, y de Honna \& Goto (82) (en Arabidopsis) quienes postulan que diferentes 
combinaciones (ternas o cuaternas) de proteinas MADS-box activarán diferentes genes en cada verticilo.

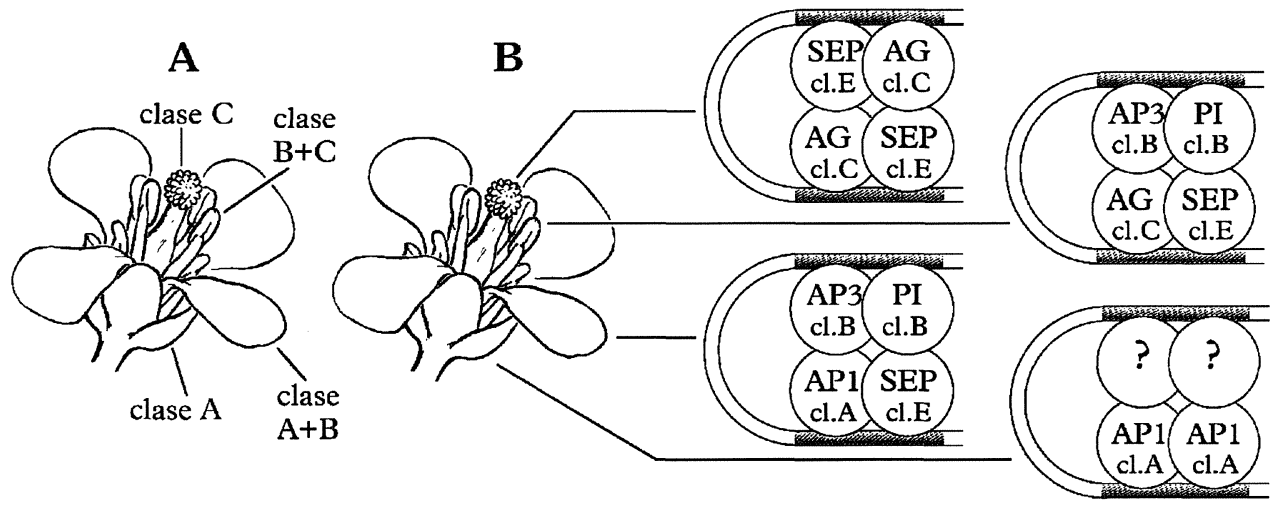

Figura 1. A: modelo «en cascada» de los tipos (clases) de genes que intervienen en la morfogénesis floral. B: modelo «del cuarteto» con especificación de los genes de cada clase que intervienen en la determinación de los órganos florales. Basada en referencia 80.

El modelo del cuarteto propone que la identidad de los órganos florales está ligada a la acción de cuatro complejos tetraméricos (factores de transcripción) compuestos por proteinas MADS-box. Así los sépalos serían especificados por dos genes de clase $\mathrm{A}$ y otros dos desconocidos (¿clase $\mathrm{E}$ ?); los pétalos por dos genes de clase $\mathrm{B}$, uno de $\mathrm{A}$ y otro de $\mathrm{E}$; los estambres por dos genes de clase $\mathrm{B}$, otro de clase $\mathrm{C}$ y el cuarto de clase $\mathrm{E}$ y los carpelos por dos genes de clase $\mathrm{C}$ y otros dos de clase $\mathrm{E}$ (fig.1).

Probando si la cascada es universal en angiospermas, Kramer \& al (83) hallan que en las basales (incluso en ranuncúlidas) sólo hay un gen AP3 (paleo-AP3) mientras que en las demás eudicotiledóneas, se multiplica (AP3 1, AP3 2, AP3 3); también que, en ranuncúlidas, el comportamiento de los parálogos AP3 y PI (clase B) no es uniforme en cuanto a la determinación de pétalos: en papaveráceas se expresan, como en el resto de las eudicotiledóneas, en pétalos y estambres (y en tegumentos ovulares) pero en ranunculáceas lo hacen o no en pétalos para cuya formación intervienen otros genes no identificados. Caben pues, como se sabía, dos orígenes para los pétalos: el que los relaciona con brácteas y el que lo hace con estambres.

Con respecto a la simetría floral, se conocen desde antiguo mutaciones que la modifican pero sólo recientemente se ha aislado el gen CYC responsable de la bilateralidad de la flor de Antirrhinum (84). Igualmente (85) la forma mutante (metilada e inactiva) de su homólogo en Linaria 
también produce flores regulares; ocasionalmente el mutante revierte durante el desarrollo (desmetilación). Flores zigomorfas se han producido numerosas veces en el curso evolutivo de las angiospermas. Algunos géneros producen flores regulares en posición terminal y zigomorfas en posición lateral, ello se debe a que el gen CYC no actúa en el meristemo apical.

Sobre el silencio de los genes (en Arabidopsis) y su relación con el estado metilado de los mismos se halla mayor complejidad de la esperada ya que algunos «despiertan» mientras siguen metilados en tanto que otros, no metilados, guardan silencio (86).

Parece claro que son aún más las preguntas que las respuestas conseguidas en el tema de la morfogénesis vegetal, pero también que los genes homeóticos son fundamentales tanto para unidad (permanencia de la especie como tal) como para la diversidad de la morfología (87); los complejos homeóticos son básicamente conservadores pero también sufren cambios (de secuencia, duplicaciones de genes, pérdidas o ganancias, inversiones, etc. (88) y tales alteraciones en este genoma regulador, responsable de la morfogénesis, permite la surgencia súbita de estructuras nuevas sin la incorporación de nuevos alelos en la población; pero, incluso sin los cambios antedichos, basta con ciertos «errores» en el orden, en el lugar o en el momento de expresión de los genes homeóticos para que se produzcan cambios importantes en el fenotipo; son indudablemente una fuente de variación no gradual, capaz de generar nuevos diseños. Alteraciones de este tipo también permiten explicar las explosiones evolutivas producidas en un tiempo limitado ya que pueden proporcionar una gran diversidad fenotípica partiendo de sólo unos pocos genes.

De otras morfogénesis: En el mundo de las bacterias también se considera el tema de la morfogénesis. Así se ha demostrado (89) que Anabaena (una cianobacteria) sabe contar hasta 10 y cada 10 células normales fabrica un heterociste; posee genes para la diferenciación o para la represión de los mismos. Otras bacterias no sólo «saben aritmética» sino que también «entienden de demografía»: son capaces de censar los efectivos de su propia especie y de las ajenas, modificando su modo de crecimiento y agregación en función de los resultados obtenidos. Poseen varios lenguajes químicos y la misma o diferentes especies pueden trabajar juntas, portándose como un organismo multicelular, para dividir el trabajo (segregar enzimas que inactivan a los antibióticos o mucílagos para evitar la desecación...); saben coordinar actividades (como segregar actinas al unisono) y producir (o detener) en el momento exacto las hormonas de agregación; saben organizarse en 
diferentes tipos de agregados (colonias, filamentos, etc.), con la ventaja (para ellas) de que algunos de éstos (p. ej. el modelo biofilm) no son atacados por los antibióticos, los detergentes o el sistema inmunitario. Las más de las veces se desconocen las bases genéticas (y morfogenéticas) para estos procesos y se pone de manifiesto que tenemos que abrir más los ojos a la dimensión de la cooperación en los fenómenos de la vida y de su diversidad.

Entre los protista es común la complejidad de sus ciclos biológicos; así por ejemplo, una misma especie dinoflagelada puede ser sucesivamente flagelado pelágico, cocoide parásito de peces, «quiste» grande o mediano o pequeño, «ameba» enorme lobosa bentónica, «ameba» pequeña filosa, cocoide parásito de algas...y cada fase puede contener plasto o no $(90,91,92)$ (fig. 2); los mismos genes «saben» elaborar diseños muy diferentes que permiten a la especie la explotación de recursos diversos en el espacio y en el tiempo. El estudio de la morfogénesis en estos y en tantos otros casos análogos es también una asignatura pendiente.

Asignatura pendiente es además el estudio de la morfogénesis en el mundo fúngico. Los hongos suelen presentar una enorme plasticidad fenotípica: una misma especie sabe crecer como levadura o como micelio y éste puede ser de hifas laxas o apretadas en denso plecténquima, todo ello está claramente regulado aunque no se sabe cómo.

2d. Puede haber variación en el nivel de las poblaciones: mutaciones, recombinación (mediada por la reproducción sexual), etc. darán lugar a la presencia de diferentes alelos en la población. Pero tal (micro)variación se traduce en polimorfismos (continuos cuantitativos) en el seno de las poblaciones o entre éstas (en el seno de la especie), lo que parece tener importancia en la obtención de «ajustes locales» dando una oportunidad a la colonización de hábitats diversos, aunque no parece la base (por lo menos no la única) del origen de nuevas especies (discontinuidades cualitativas) ni siquiera por medio de dilatados periodos de tiempo.

Sería el caso de las mariposas, primero blancas sobre abedules blancos, luego oscuras sobre abedules ensombrecidos por la carbonilla de la revolución industrial, ahora volviendo a blanquear (unas y otros) gracias a la sustitución del carbón por el petróleo: blancas o negras no dejan de ser la misma especie. $O$ de nuestras razas blancas que si no lo fueran padecerían raquitismo en los umbrosos paises del norte donde tendrían dificultades para asimilar la vitamina $\mathrm{D}$, pero blancos o negros todos somos Homo sapiens. O de los pájaros que cruzan los Himalayas que, de las varias posibles, usan preferentemente las hemoglobinas con mayor afinidad por el oxígeno... 


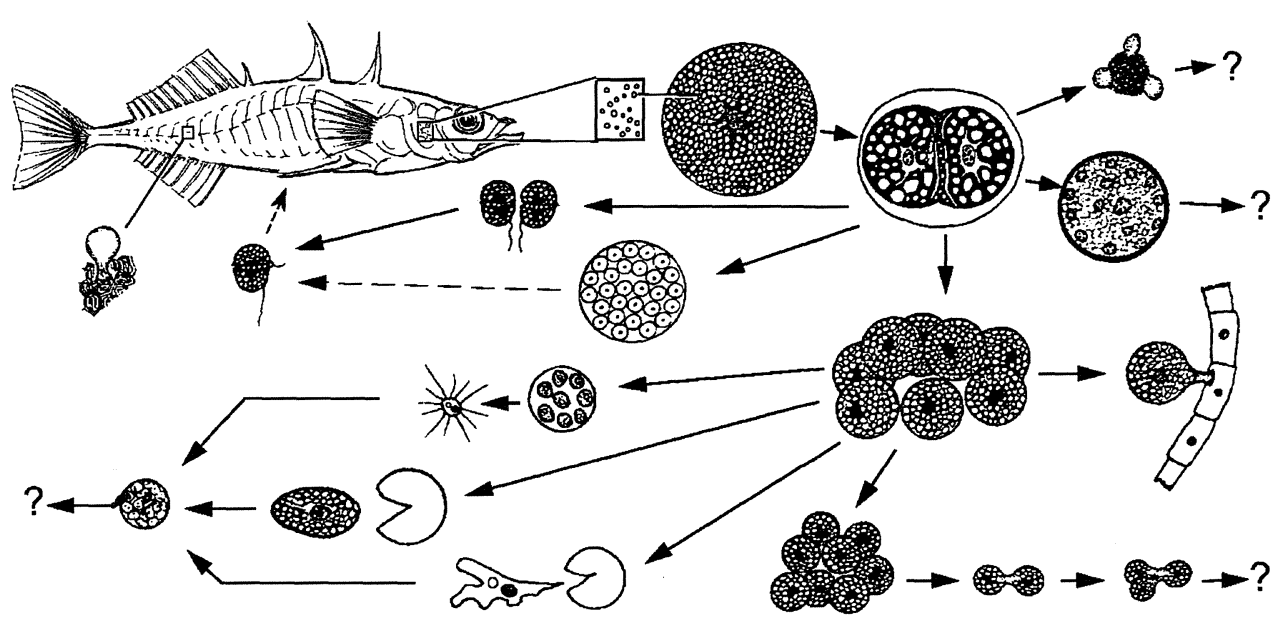

Figura 2. Sucesivos fenotipos de una especie dinoflagelada. De Buckland-Nicks, J. \& Reimchen,T.E. (90), simplificado, modificado y vuelto a componer.

Volviendo a la idea de Carson (53), la variación de alelos en la población parece corresponder a la permitida por la parte abierta del programa genético especifico. $Y$ debe ser ésta la que se moviliza y manifiesta en las razas o variedades sometidas a selección artificial, las cuales pueden poseer fenotipos muy desviados de la forma salvaje, aunque no dejan de pertenecer a la misma especie. Es lo que parece deducirse de los resultados obtenidos por Balick (93) quien plantó semillas de variedades de cultivo que llevaban décadas encapsuladas y conservadas en un banco de germoplasma, con la intención de comprobar su capacidad germinativa; la sorpresa fué que las plantas obtenidas no mostraban las características que les hacían pertenecer a una u otra variedad sino que todas se parecían al tipo silvestre. ¿Qué ha sucedido en su $\mathrm{ADN}$, durante las décadas de conservación, para que se «haya purgado» la variación poco relevante y mantenido «lo fundamental»?.

Otros descubrimientos proporcionan más claves acerca de cómo se puede producir variación en la parte cerrada del sistema genético específico. Es el caso de las proteinas de respuesta al estrés (= de choque térmico), cuya función en tiempos «normales» parece ser la de reparar el $A D N$ pero que, en tiempos de crisis, deben ocuparse (son chaperoninas) de restaurar a otras proteinas (alteradas por las condiciones adversas) a fin de que el organismo siga funcionando; desatienden así su misión primordial (lo urgente impide acometer lo importante) con el re- 
sultado de una acumulación de cambios en el ADN (cuyas consecuencias son impredecibles). Igualmente, existe un sistema "SOS bacteriano» que promueve mutagénesis (redisposiciones génicas, escisiones, transposiciones y recombinacion) y que se activa en condiciones adversas. Hechos como estos abren también una puerta a la posibilidad de variación súbita y drástica como la que es necesaria para provocar las explosiones evolutivas que siguen a las crisis ambientales y a las extinciones masivas.

En la dimensión de la comunicación también parecen estar involucradas las proteinas de respuesta al estrés. Se sabe de plantas que desencadenan defensas cuando detectan sustancia volátiles emitidas por sus congéneres dañados $(94,95)$ y también que tienen memoria (química): determinados estímulos provocan respuesta sea en la región afectada o en tejidos alejados de ésta y sea inmediata o diferida; esto supone capacidad para procesar datos del entorno, almacenar información, recuperarla en un momento dado y transmitirla por todo el cuerpo vegetal (96); se desconocen los mecanismos responsables de estos procesos aunque parece haber relación con el estado iónico de la planta y con la actividad de ciertos genes (que codifican proteinas antiestrés). Un experimento en el mismo sentido (97) consistió en exponer algunas hojas de Arabidopsis a un exceso de luz (que inhibe la fotosíntesis) con el resultado de que éstas enviaron señales al resto que comenzaron a producir antioxidantes para protegerse de un exceso lumínico que no estaban sufriendo. Memoria, cooperación y comunicación, operando desde el nivel molecular hasta (al menos) el organísmico, cuya dimensión evolutiva apenas comenzamos a vislumbrar.

Acerca de la relación entre variabilidad, tamaño de la población y reproducción sexual, Simpson (11) consideró la posibilidad de evolución rápida en poblaciones pequeñas (deriva genética) como excepción a la norma mantenida por el paradigma neodarwinista en el que la tasa de cambio evolutivo se considera proporcional a la diversidad genética disponible, ésta será mayor en las poblaciones amplias y panmícticas que en las reducidas con cruzamiento menos aleatorio, de suerte que las primeras poseerán no sólo mayor éxito sino también mayor potencial evolutivo. En este marco, Stebbins (98) consideraba a las plantas raras (escasas y en poblaciones pequeñas) como genéticamente depauperadas pero cambió de opinión (99) cuando encontró altos niveles de variabilidad en algunas de ellas a la vez que variabilidad escasa en especies muy comunes y formadoras de poblaciones amplias.

Parece así que los niveles de variabilidad no guardan relación con el tamaño de la población (ni por tanto con el cruzamiento panmíctico) sino 
con la filiación de las especies (constricción filogenética): raras o comunes estrechamente emparentadas mostrarán similares (altos o bajos) niveles de variabilidad (100). También en poblaciones reducidas de Drosophila (101) se ha hallado tanta o más variabilidad que en las amplias panmícticas.

Incluso, el esperado incremento de variabilidad mediado por la reproducción sexual parece una predicción que tampoco se cumple: numerosos son los casos de plantas autógamas que portan un alto nivel de variabilidad (7) y lo mismo sucede en hongos que han perdido sus ciclos sexuales y se multiplican sólo vegetativamente $(102,103)$.

2e. Y puede haber variación por integración de especies (simbiosis y otras adiciones de información): La integración de organismos completos en la génesis de nuevos diseños parece haber sido la causa del origen de la célula eucariótica. Se discute sobre su naturaleza quimérica como nacida de la unión de una Archaea y una o varias Bacteria $(104,105,106$, 107, 108, 109, 110; pero ver 111, 112 para hipótesis alternativas). A esta quimera se añadió una nueva bacteria endosimbionte (pariente ancestral de las modernas rickettsias) que se transformó en mitocondria.

Y, complicando más las cosas, una estirpe eucariótica (fagotrofa de origen) captó una cianobacteria a la que transformó en plasto primario (directamente bacteriano); tal estirpe, la primera eucariótica fotosintetizadora, se ramificaría con el tiempo en glaucófitos, algas rojas y verdes (fig. 3). Se ha prestado mucha atención a mitocondria y plasto y muy poca a la pléyade de bacterias diversas que son comunes en el citoplasma de los eucariontes unicelulares; de muchas se sabe que han transferido parte de su genoma al núcleo, de otras que proporcionan vitaminas a la célula principal. Peroxisomas, hidrogenosomas y otros «orgánulos» quizá tienen su origen también en antiguas endosimbiosis.

Por si esto era poco, aquellos eucariontes autotrofos (portadores de al menos tres genomas: núcleo, mitocondria y plasto primario, integrados y cooperantes) también pudieron ser «cazados» por otros eucariontes fagotrofos, a los que convirtieron en fotosintetizadores, transformándose ellos mismos en plastos secundarios (de origen eucariótico) dentro de aquellos. Y la rueda siguió girando.

Así una estirpe euglénida (pero no todas: hay euglénidos primariamente aplastídicos) captó un alga verde que convirtió en euglenoplasto tras reducirla drásticamente $(113,114,115)$. La rama ancestral de los criptófitos incorporó un alga roja (116 y ref. contenidas) que también fué reducida aunque conservando su núcleo vestigial (117). Igualmente el ancestro de los primnesiófitos (= haptófitos o cocolitofóridos) independientemente, captó y redujo a un alga roja diferente (118). 


\section{Botánica y Evolución}

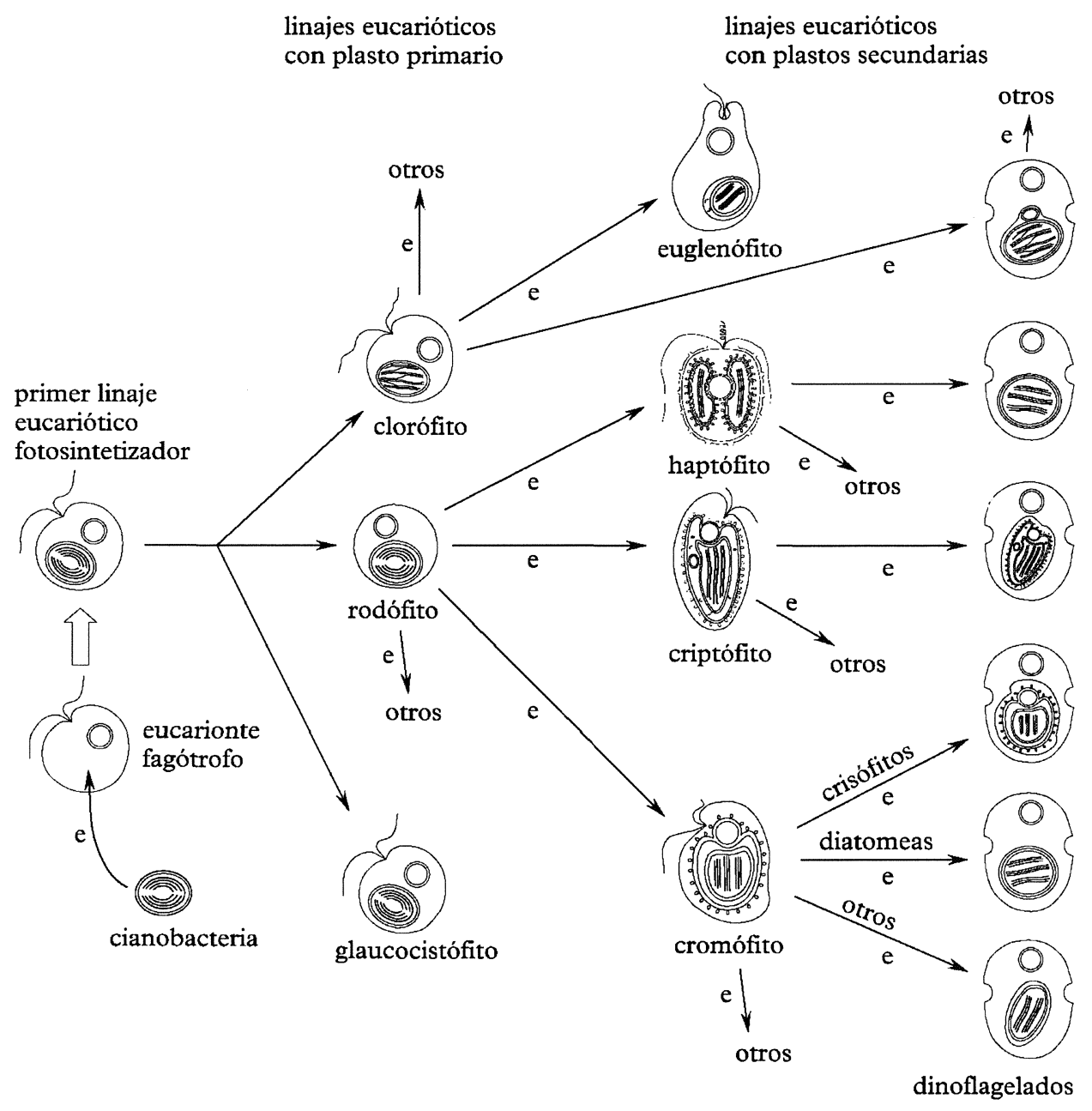

FIGURA 3. Esquema del origen de los plastos primarios y secundarios. e=endosimbiosis.

Más compleja es la historia de los plastos del conjunto pardo-dorado: quizá el antepasado común a sus linajes fotosintetizadores y pseudofúngicos (laberintúlidos y oomicetes, diatomeas, crisófitos, xantófitos, algas pardas, pelagoficeas, silicoflagelados y pedinélidos) incorporó un alga roja unicelular $(119,120)$ que fué reducida a crisoplasto; especies individuales o ramas enteras (como los laberintúlidos y oomicetes) lo perdieron secundariamente (algunas retienen mancha ocular como resto del mismo). Pero el plasto de eustigmatofíceas y, sobre todo los de rafidofíceas 
(=cloromónadas) parecen tener otros orígenes: quizá perdieron su crisoplasto original y lo sustituyeron mediante la captura de un pariente, $\mathrm{p}$. ej. xantofíceo u otro, más o menos próximo (121).

«Amebas reticulares» como Chlorarachnion portan plastos (con su propio núcleo) que parecen afiliarse con las algas verdes (122) mientras que otras «redes de babas» como Reticulosphaera los tienen de tipo crisoplasto.

Entre los dinoflagelados hay estirpes primariamente aplastídicas y otras fotosintetizadoras pero sus plastos son de origen diverso, lo que implica varias endosimbiosis independientes de algas rojas, verdes, haptófitos, diatomeas, crisófitos o criptófitos $(123,124,125,126,127$ y ref. cont.) todos ellos más o menos reducidos, conservando o no sus propios núcleos. De alguna rama dinoflagelada autotrofa debieron escindirse los apicomplejos (p. ej. Plasmodium) pues contienen un plasto residual (128, 129) aunque derivaron hacia el parasitismo (antes clasificados en el polifilético grupo de los esporozoos).

Nunca estudiados en la Botánica pese a que muchos de ellos fotosintetizan (y algunos llegan a ser importantes productores primarios) son los ciliados, foraminíferos, radiolarios, acantarios, corales, esponjas, cnidarios, turbelarios, moluscos, platelmintos, equinodermos, ascidias, renacuajos..., los cuales pueden tener como endosimbiontes a cianobacterias, algas verdes, dinoflagelados, crisofíceas, xantofíceas, diatomeas o haptofíceas. Piénsese en el número de genomas que conviven armoniosamente, por ejemplo, en un cliado fotosintetizador gracias a un endosimbionte dinoflagelado (pariente a fin de cuentas) cuyo plasto sea un criptófito: el del nucleo del ciliado, de su mitocondria, del núcleo dinoflagelado, de su mitocondria, del núcleo criptofítico, de su mitocondria, del nucleo vestigial del alga roja (no conserva mitocondria) y el de la cianobacteria o plasto primario; y en los finos mecanismos de regulación y de comunicación molecular que deben desplegarse para conseguirlo.

El caso paradigmático de (exo)simbiosis en el mundo vegetal lo proporcionan los líquenes, organismos plurigenómicos (aunque también los casos mencionados más arriba lo son) que para Tibell (130) están tan altamente integrados que el éxito de ambos por separado se aproxima a cero.

También es de interés la asociación de los hongos (micorrizas) con las raíces de las plantas, ya presente en fósiles de más de $400 \mathrm{Ma}(131,132$ y ref. contenidas). Para algunos (133) la colonización de la tierra firme por las plantas no hubiera sido posible sin su asociación con los hongos; otros consideran que los hongos pudieron haber sido los inductores de la lignificación vegetal e incluso (134) que el ancestro carofíceo de Planta adquirió el crecimiento apical (que le confirió la capacidad de formar te- 
jidos) mediante asociación temprana con hongos simbióticos y gracias al $\mathrm{ADN}$ que éstos le cedieron.

La compatibilidad planta-hongo implica complejos procesos de reconocimiento y coordinación molecular entre ambos: la raíz induce la germinación sólo de las esporas deseadas y elimina las respuestas defensivas; alteraciones en la morfogénesis celular permiten la penetración de la hifa, etc. (135): se trata de mecanismos muy diferentes a los expresados frente a los patógenos. Por otra parte, las micorrizas no sólo proporcionan agua y nutrientes a la planta sino que también provocan cambios morfológicos: en gramíneas C4 determinan un incremento de la estela y con ello del tamaño de la planta (136). Pero además de micorrizas hay hongos en las partes aéreas de muchas plantas que, con frecuencia les proporcionan mayor vigor y tasa de supervivencia quizá porque las protegen de ataques de insectos, de otros hongos o bacterias etc. Estas asociaciones se conocen desde hepáticas en adelante, y quizá se establecieron ya en el Ordovícico.

De parecida naturaleza debe ser la simbiosis de algunas plantas con bacterias rizobiales, las cuales también les ceden $\mathrm{ADN}$, desarrollando complejos sistemas de comunicación entre ambas e involucrando genes de reconocimiento; como en el caso de las microrrizas, una vez establecida la simbiosis con bacterias, se evitan otras infecciones. Son también numerosos los casos descritos de asociaciones (ecto y endocelulares) de cianobacterias con plantas.

En los procesos de simbiosis, hay una componente ecológica y otra evolutiva; en ciertos casos, la asociación incrementa (o posibilita) la eficiencia ecológica de al menos una de las estirpes pero no origina otra nueva: un caracol o un renacuajo "fotosintetizadores» pueden explotar ambientes pobres en nutrientes pero no dejan de ser un caracol o un anfibio. La dimensión evolutiva de la simbiosis como generadora de diseños novedosos, está fuera de toda duda en el origen de la célula eucariótica, también en el origen de los líquenes y en de los primeros eucariontes fotosintetizadores: aquel pequeño flagelado fagotrofo que incorporó a una cianobacteria se constituyó en una línea radicalmente diferente; $y$, si tal evento no hubiera sucedido, no hubiera sido posible la cascada de endosimbiosis que dió lugar a las diferentes líneas algales con plastos secundarios; tampoco existirían las plantas terrestres que son, en definitiva, descendientes de una rama de algas verdes. De ser ciertos los postulados de Pirozinsky y Mallok, no hubiera sido posible el establecimiento de las plantas sobre la tierra firme.

Con respecto a otras adiciones de $\mathrm{ADN}$, también está fuera de toda duda la transferencia horizontal entre diferentes estirpes (con conse- 
cuencias impredecibles), entre simbiontes e incluso desde (o hacia) parásitos; un agente infeccioso bacteriano puede transformarse en endosimbionte en pocos años (137). Las bacterias pueden tomar ADN libre (138 y ref. contenidas) lo que debió tener su importancia en la evolución celular temprana. Bien conocida es la transferencia de secuencias entre bacterias de la misma o distinta especie, sea mediada por conjugación, fagos o transposones $(139,140,141)$; pero también se ha documentado el paso de genes desde Bacteria a Archaea; no parecen raros los intercambios entre plasto y mitocondria $(142,143)$, así el plasto de las algas rojas (rodoplasto) debió perder uno de los genes necesarios para la síntesis de Rubisco, pero lo repuso con el transferido de su propia mitocondria (144). Y están bien documentados los trasiegos masivos de genes de ambos (mitocondria y plasto) al núcleo eucariótico (en Planta, entre el 3 y el 7\% de su ADN es de origen organular (145); al parecer la pérdida masiva de genes organulares fue temprana y rápida habiendo habido después algunas pérdidas diferenciales entre estirpes (146).

También se conocen genes eucarióticos que se han incorporado en bacterias: Escherichia coli tiene un gen de Planta, genes animales aparecen en otras Bacteria (147 y ref. contenidas), llamativo es el caso de genes de un áfido imprescindibles para su desarrollo larvario pero que residen en su bacteria endosimbionte (148), y Mycobacterium tuberculosis contiene, al menos, ocho genes humanos (149). Otro ejemplo de intercambio de genes entre organismos de diferentes reinos es el de un intrón móvil del ADN mitocondrial de muchas angiospermas que parece llegado desde Fungi mediante c. 1000 eventos de transferencia en una ola masiva y reciente de invasión (150).

Parece pues que las barreras al trasiego de $\mathrm{ADN}$ entre especies distintas son sorteables, que las transferencias masivas (aunque raras) se realizan muy rápidamente, que por lo común no parecen tener grandes consecuencias fenotípicas en el que recibe los genes, bien porque éstos se «purgan» o se silencian, se integran «sin hacer ruido» o se utilizan para otros fines; en este sentido se conocen en Bacteria sistemas enzimáticos para reparar su ADN usando el recién incorporado y eliminando el erróneo; algunos autores (151) consideran que el origen del sexo puede tener relación con la necesidad de tomar $\mathrm{ADN}$ foráneo para la reparación del propio y que, en Eukarya, con alguna sofisticación mayor, la fusión y segregación de cromosomas permite igualmente purgar los parásitos moleculares; es ésta una interpretación bien diferente a la tradicional que pone el sexo al sevicio de la recombinación de alelos.

Pero la incorporación de genes también puede tener consecuencias evolutivas ya que, como se ha visto, la inserción de secuencias en según 
qué lugares puede modificar la expresión de los genes aledaños. En este sentido se piensa en el ADN móvil (que con frecuencia es de origen viral) como elemento capaz de generar novedades evolutivas. Los ubicuos virus pueden ser vehículos de ADN y la alta cantidad de secuencias virales halladas en los genomas secuenciados, incluido el humano (recuérdese también el caso de Hordeum citado más arriba) así parecen atestiguarlo. Fuhrman (152) informa de la existencia de una formidable cantidad (c. 10.000 millones / litro) de virus marinos y de su importancia real tanto en los procesos ecológicos y biogeoquímicos como en la probable debida a su capacidad para la transferencia genética; ésta podría tener lugar en periodos de crisis mediante, por ejemplo, transgresiones marinas. Schwemmler (153) propone un modelo evolutivo que denomina endocitobiológico, basado en transferencias horizontales mediadas por virus y bacterias que jugarían a reactivar genes silentes.

Una infección vírica puede afectar a la vez a numerosos individuos de una población (y más en situaciones de estrés); si su inserción en el genoma de los mismos no se produce al azar sino en algún lugar preciso (como parece la norma), muchos portarán idéntica «mutación»; si las consecuencias de tal inserción afectan a la parte cerrada del programa genético, en la morfogénesis de la generación siguiente se producirán numerosos «monstruos» (iguales entre sí y distintos de sus parentales) que tal vez serán los nuevos «diseños óptimos» de Niklas. Quizá de esta manera el «monstruo» solitario de Goldschmidt encuentra compañeros; quizá es así como surge una nueva especie.

Parece que, además de la génesis de nuevos diseños mediante la integración de simbiontes, existe también posibilidad de evolución de nuevas estirpes debida a estas secuencias transferidas (integración igualmente de entidades aunque, en este caso, moleculares) materia prima para sucesivas redisposiciones de genes, regulaciones diferentes, etc. Es evidente que, mas allá de los lentos cambios cuantitativos en las frecuencias alélicas, existen otros mecanismos que proporcionan variación súbita y la posibilidad de génesis de nuevos tipos.

3. De la competencia y la selección natural: finalmente, en el paradigma darwiniano, se canaliza la variabilidad mediante competencia y selección natural: una vez producidas las variantes se establece competencia entre sus portadores, sobreviviendo (y perpetuando sus genes) los más aptos, elegidos y promocionados por la selección natural; pero muchos de los procesos descritos más arriba pueden ser sendas fuentes de novedades evolutivas súbitas sin necesidad de competencia y de selección natural; por el contrario, requieren de autoorganización y cooperación, sea en el nivel molecular, celular u organísmico (154). 


\section{Margarita Moreno}

\section{A modo de conclusión}

Parece que, tras un largo periodo de ciencia reduccionista que se instauró con el crecimiento de las disciplinas de la Biología funcional en detrimento de las de la Biología sistemática o evolutiva (pero que también afectó a ésta) estamos en un momento de recuperación del interés por los procesos del cambio evolutivo. Pero no sólo, sino que también parece haberse desarrollado la voluntad de poner en común los saberes procedentes de distintas aproximaciones, la consecuencia es que se están produciendo muy rápidamente nuevos y mejores frutos.

\section{Bibliografía}

1. Olsen, G. J., Woese, C. R. \& Overbeek, R. (1994) The winds of (Evolutionary) change: Breathing new life into Microbiology. J. Bacteriol, 176(1): 1-6).

2. Margulis, L. \& Schwartz, K. V. (1982) Los cinco Reinos. Freeman \& Co. N.Y.

3. Schopf, J. W. (1999) Cradle of life. Princeton Univ. Press. N.J.

4. Rayner, A. D. M.; Brasier, C. M. \& Moore, D. (Eds.) (1986) Evolutionary Biology and the fungi.Cambridge Univ. Press, Cambridge.

5. Grant, V. (1980) Plant speciation. Columbia Univ. Press, N.Y.

6. Grant, V. (1991) The evolutionary process. Columbia Univ. Press, N.Y.

7. Stebbins, G. L. (1950) Variation and evolution in plants. Columbia Univ. Press, New York

8. StebBins, G. L. (1974) Flowering plants. Evolution above the species level. Belknap Press, Cambridge, Mass.

9. NiKLAS, K. J. (1997) The evolutionary biology of plants.The University of Chicago Press, Chicago.

10. MAYR, E. (1963) Animal species and evolution. Belknap Press, Cambridge, Mass.

11. Simpson, G. G. (1944) Tempo and mode in evolution. Columbia Univ. Press, N.Y.

12. Elderedge, N. \& Gould, S. J. (1972) Punctuated equilibria: an alternative to phyletic gradualism. in T.J.M. SchOpF, ed., Models in Paleobiology. Freeman, San Francisco. pp. 82-115.

13. Gould, S. J. (1994) Tempo and mode in the macroevolutionary reconstruction of darwinism, Proc. Natl. Acad. Sci. USA, 91(15): 6764-6771.

14. Sandín, M. (1997) Teoría Sintética: Crisis y Revolución. Arbor 158:269-303

15. KNoll, A. H. (1992) The early evolution of eukaryotes: A geological perspective. Science, 256: 622-627.

16. Foote, M. and Sepkoski, J. J. (1999) Absolute measures of the completeness of the fossil record. Nature, 398: 415-417.

17. Valentine, J. W. (1994) Late Precambrian bilaterians: Grades and clades. Proc. Natl. Acad. Sci. USA, 91(15):6751-6757

18. Benton, M. J. (1995) Diversification and extinction in the history of life. Science, 268(5207): 52-58.

19. SCHOPF, J. W. (1994) Disparate rates, differing fates: Tempo and mode of evolution changed from the Precambrian to the Phanerozoic. Proc Natl. Acad. Sci. USA 91(15): 6735-6742. 


\section{Botánica y Evolución}

20. Fitch, W. M. \& Ayala, F. J. (1994) Tempo and mode in evolution. Proc. Natl. Acad. Sci. USA, 91(15): 6717-6720.

21. Raup, D. M. (1994) The role of extinction in evolution. Proc Natl. Acad. Sci. USA 91(15):6758-6763

22. KNOLL, A. H. (1985) The distribution and evolution of microbial life in the Late Proterozoic Era. Annu. Rev. Microbiol., 39: 391-417.

23. Kirschvink, J. L , Gaidos, E. J., Bertani, L. E., Beukes, N. J., JGutzmer, J. , MAePA, L. N. \& Steinberger, E. E. (2000) Paleoproterozoic snowball Earth: Extreme climatic and geochemical global change and its biological consequences. Proc. Natl. Acad. Sci. USA, 97: 1400-1405.

24. Mojzsis, S. J., Arrhenius, K. D., McKeegan, K. D., Harrison, T. M., Nutman, A. P. \& FRIENDS, C. R. L. (1996) Evidence for life on Earth before 3.800 million years ago. Nature 384: 55-59.

25. Sснорғ, J. W. (1968) Microflora of the Bitter Springs Formation, Late Precambrian, central Australia. J. Paleont., 42(3): 651-688.

26. Schopf, J. W. \& WALTER, M. R. (1983). Archean microfossils: New evidence of ancient microbes. In Schopf, J. W., Ed., Earth's Earliest Biosphere: Its Origin and Evolution, 214-239. Princeton Univ. Press. N.J.

27. Doolittle, W. F. (1999) Phylogenetic classification and the universal tree. Science, 284(5423): 2124-2129.

28. Feng, D. F., Cho, G. \& Doolittle, R. F. (1997) Determining divergence times with a protein clock: update and reevaluation. Proc. Natl. Acad. Sci. U S A, 94(24): 13028-33.

29. KNoll, A. H. (1992) The early evolution of eukaryotes: A geological perspective. Science, 256: 622-627.

30. BELFORT, M. (1991) Self-splicing introns in Prokaryotes: migrant fossils?. Cell, 64(1): 9-11.

31. Fitch, W. M. \& Ayala, F. J. (1994) Tempo and mode in evolution. Proc. Natl. Acad. Sci. USA, 91(15): 6717-6720.

32. KNoll, A. H. (1985) The distribution and evolution of microbial life in the Late Proterozoic Era. Annu. Rev. Microbiol., 39: 391-417.

33. Escalante, A. A. \& Ayala, F. J. (1995) Evolutionary origin of Plasmodium and other Apicomplexa based on rRNA genes. Proc Natl. Acad. Sci. USA, 92: 5793-5797.

34. PAGEL, M. (1999) Inferring the historical patterns of biological evolution. Nature, 401(6756): 877-884.

35. KNOLL, A. H. (1994).Proterozoic and early cambrian protists: Evidence for accelerating evolutionary tempo. Proc. Natl. Acad. Sci. USA, 91(15): 6743-6750.

36. Tappan, H. L. (1980) Paleobiology of Plant Protists. Freeman. San Francisco.

37. BURNETT, J. H (1986) Aspects of the macro- and microevolution of the fungi. in RAYNER, A. D. M. \& al., eds., (1986) Evolutionary Biology and the fungi. pp. 1-15. Cambridge Univ. Press, Cambridge.

38. BERBEe, M. L. \& TAYLOัR, J. W. (1993) Dating the evolutionary radiations of the true Fungi. Can. J. Bot., 71(8): 1114-1127.

39. TAYLOR, W. A. (1995) Spores in earliest land plants. Nature, 373: 391-392.

40. KenRICH, P. \& CRANE, P. R. (1997) The origin ans early evolution of plants on land. Nature, 389: 33-39).

41. Meyer-Berthaud, B., Scheckler, S. E. \& Wendt, J. (1999) Archaeopteris is the earliest known modern tree. Nature, 398: 700-701 


\section{Margarita Moreno}

42. TAYLOR, T.N. \& TAYLOR, E.D. (1993) The biology and evolution of fossil plants. Prentice Hall.

43. McElwain, J. C., Beerling, D. J. \& Woodward, F. I. (1999) Fossil plants and global warming at the Triassic-Jurassic boundary. Science, 285: 1386-1389.

44. Fortey, R. (1999) La vida. Una biografia no autorizada. Taurus. Madrid.

45. Nido, J. del, Gómez Manzaneque, F., Masedo, F., Morla, C., Roig, S. \& SÁnchez HERNANDO, L. J. (1998) Identificación de un dendrolito en el Cretácico Inferior (Aptiense) del Sistema Ibérico septentrional (La Rioja, España). Consideraciones paleoambientales. Rev. Paléobiol., 17(2): 513-523.

46. Crane, P. R., Friis, E. M., \& Pedersen, K. R. (1995) The origin and early diversification of angiosperms. Nature, 374(6517): 27-33.

47. FriIs, E. M., Pedersen, K. R. \& CRANe, P. R. (1999) Early angiosperm diversification: the diversity of pollen associated with angiosperm reproductive structures in Early Cretaceous floras from Portugal. Ann. Mo. Bot. Gard., 86: 259-296.

48. PACE, N. R. (1997) A molecular view of microbial diversity and the biosphere. Science, 276(5313): 734-740.

49. Cavalier-Smith, T., Chao, E. E., \& Allsopp, M. T. E. P. (1995) Ribosomal RNA evidence for chloroplast loss within Heterokonta: Pedinellid relationships and a revised classification of Ochristan algae. Arch. Protistenk., 145(3-4): 209-220.

50. Freshwater, D. W., Fredericq, S., Butler, B. S., Hommersand, M. H. \& Chase, M. W. (1994) A gene phylogeny of the red algae (Rhodophyta) based on plastid rbcL Proc. Natl. Acad. Sci. USA, 91: 7281-7285.

51. Hasebe, M., Wolf, P. G., Pryer, K. M., Ueda, K., Ito, M., Sano, R., Gastony, G. J., Yokoyama, J., Manhart, J. R., Murakami, N., Crane, E. H., Haufler, C. H. \& Hauk, W. D. (1995) Fern phylogeny based on rbcL nucleotide sequences. Amer. Fern J., 85(4): 134-181.

52. Chase, M. W., Soltis, D. E., Olmstead. R. G., Morgan, D., Les, D. H., Mishler, B. D., Duvall, M. R., Price, R. A., Hills, H. G., QIU, Y. L., Kron, K. A., RetTig, J. H., Conti, E., Palmer, J. D., Manhart, J. R., Sytsma, K. J., Michaels, H. J., Kress, W. J., Karol. K. G., Clark, W. D., Hedren, M., Gaut, B. S., Jansen, R. K., Kim, K. J., Wimpee, C. F., Smith, J. F., Furnier, G. R., Strauss, S. H., Xiang, Q. Y., Plunkett, G. M., Soltis, P. S., Swensen, S. M., Williams, S. E., Gadek, P. A., Quinn, C. J., Eguiarte, L. E., Golenberg, E., Learn, G. H., Graham, S. W., Barrett, S. C. H., DAYANANDAN, S. \& AlBert, V. A. (1993). Phylogenetics of seed plants. An analysis of nucleotide sequences from the plastid gene RbcL. Ann. Mo Bot. Gard., 80(3): 528-580.

53. CARSON, H. L. (1987) The genetic system, the deme and the origin of species. Annu. Rev. Genet., 21:405-423.

54. Suoniemi, A., Schmidt, D. \& Schulman, A. H. (1997) BARE-1 insertion site preferences and evolutionary conservation of RNA and cDNA processing sites. Genetica, 100(1-3): 219-230.

55. ClegG, M. T. (ed.) (1987) Plant molecular evolution. A symposium. Amer. Natur., 130, suppl.: S1-S5.

56. Schnable, P. S., Hsia, A.. P. \& NikolaU, B. J. (1998) Genetic recombination in plants. Curr. Opin. Plant Biol., 1(2): 123-129.

57. KADEREIT, J. W. (1989) Evolution and classification of seed plants. Progr. Bot., 51: 278-312.

58. Ellstrand, N. C., Whithkus, R. \& Rieseberg, L. H. (1996) Distribution of spontaneous plant hybrids. Proc. Natl. Acad. Sci. USA, 93: 5090-5093. 
59. Soltis, D. E. \& Soltis, P. S. (1993) Molecular data facilitate a reevaluation of traditional tenets of polyploid evolution. Crit. Rev. Plant Sci., 12:243-273.

60. Soltis, E. D. \& Soltis, P. S. (2000) The role of genetic and genomid attributes in the success of polyploids. Proc. Natl. Acad. Sci. USA, 97(13): 7051-7057.

61. Song, K., LU, P., TANG, K. \& OsboRn, T. (1992) Rapid genome change in synthetic polyploids of Brassica and its implications for polyploid evolution. Proc. Natl. Acad. Sci. USA, 92(17): 7719-7723.

62. Galitski, T., Saldanha, A. J., Styles, C. A., Lander, E. S. \& Fink, G. R. (1999) Ploidy regulation of gene expression. Science, 285(5425): 251-254.

63. MurRAy, J. D. (2000) Pattern formation in integrative biology -a marriage of theory and experiment. C. R. Acad. Sci. III, 323(1): 5-14.

64. GrahAM, L. E. (1982) The occurrence, evolution, and phylogenetic significance of parenchyma in Coleochaete Breb. (Chlorophyta). Amer. J. Bot., 69(3): 447-454.

65. BASILE, D. V. AND BASILE, M. R. (1987) The occurrence of cell wall-associated arabinogalactan proteins in the Hepaticae. Bryologist, 90, 401 \pm 404 .

66. BASILE, D. V. 1990. Morphoregulatory role of hydroxyproline in liverworts. In Bryophytes: Physiology and Biochemistry, pp. 225-243. R. N. CHOPRA AND S. C. BHATLA (eds.) CRC Press, Inc., Boca Raton, Fl.

67. Stebins, G. L. (1992) Comparative aspects of plant morphogenesis: a cellular, molecular, and evolutionary approach. Amer. J. Bot., 79(5): 589-598.

68. Dennis, E. S. \& Bowman, J. L. (1993) Manipulating floral organ identity. Current Biology, 3: 90-93.

69. WeIGEL, D. (1995). The genetics of flower deveopment: From floral induction to ovule morphogenesis. Annu. Rev. Genet., 29: 19-39.

70. Cashmore, A. R., Jarillo, J. A., WU, Y. J. \& LiU, D. (1999) Cryptochromes: blue light receptors for plants and animals. Science, 284(5415): 760-765.

71. Christie, J. M., Reymond, P., Powell, G. K., Bernasconi, P., Raibekas, A. A., LisCUM, E. \& BRIGGS, W. R. (1998) Arabidopsis NPH1: a flavoprotein with the properties of a photoreceptor for phototropism. Science, 282(5394): 1698-1701.

72. Schwarz-Sommer, Z., HuijSer, P., Nacken, W., Saedler, H., Sommer, H. (1990) Genetic control of flower development by homeotic genes in Antirrhinum majus. Science, 250: 931-936.

73. Coen, E. S., Romero, J. M., Doyle, S., Elliot, R., Murphy, G., and Carpenter, R. (1990) FLORICAULA: homeotic gene required for flower developmentin Antirrhinum majus. Cell, 63(6): 1311-1322.

74. Busch, M. A., Bomblies, K. \& Weigel, D. (1999) Activation of a floral homeotic gene in Arabidopsis. Science, 285(5427): 585-587.

75. Bradley, D., Ratcliffe, O., Vincent, C., Carpenter, R. \& Coen, E. (1997) Inflorescence commitment and architecture in Arabidopsis. Science, 275(5296): 80-83.

76. Coen, E. S. \& MEYerowitz, E. M. (1991) The war of the whorls: genetic interactions controlling flower development. Nature, 353(6339): 31-37.

77. WAgner, D., SABlowski, R. W. \& MeYerowitz, E. M. (1999) Transcriptional activation of APETALA1 by LEAFY. Science, 285(5427): 582-584.

78. JuRgens, G. (1997) Memorizing the floral ABC. Nature, 386(6620): 17.

79. Pelaz, S., DitTa, G. S., Baumann, E., Wisman, E. \& Yanofsky, M. F. (2000) B and C floral organ identity functions require SEPALLATA MADS-box genes. Nature, 405(6783): 200-203.

80. Theissen, G. \& Saedler, H. (2001) Plant biology. Floral quartets. Nature, 409(6819): 469-471. 


\section{Margarita Moreno}

81. Egea-Cortines, M., Saedler, H. \& Sommer, H. (1999) Ternary complex formation between the MADS-box proteins SQUAMOSA, DEFICIENS and GLOBOSA is involved in the control of floral architecture in Antirrhinum majus. Embo J., 18(19): 5370-5379.

82. Honma, T. \& GoTo, K. (2001) Complexes of MADS-box proteins are sufficient to convert leaves into floral organs. Nature, 409(6819): 525-529.

83. Kramer, E. M. \& IRISH, V. F. (1999) Evolution of genetic mechanisms controlling petal development. Nature, 399(6732): 144-148.

84. Luo, D., Carpenter, R., Vincent, C., Copsey, L. \& Coen, E. (1996) Origin of floral asymmetry in Antirrhinum. Nature, 383(6603): 794-799.

85. Cubas, P., Vincent, C. \& Coen, E. (1999) An epigenetic mutation responsible for natural variation in floral symmetry. Nature, 401(6749): 157-161.

86. Tweedie, S. \& BIRD, A. (2000) Gene expression. Mutant weed breaks silence. Nature, 405(6783): 137-138.

87. Wray, G. A. \& Abouheif, E. (1998) When is homology not homology? Curr Opin Genet Dev, 8(6): 675-680.

88. Finnerty, J. R. \& Martindale, M. Q. (1998) The evolution of the Hox cluster: insights from outgroups. Curr. Opin. Genet. Dev., 8(6): 681-687.

89. HASELKORN, R. (1998) How cyanobacteria count to 10. Science, 283: 891-892.

90. Buckland-Nicks, J. \& ReImChen, T. E. (1995) A novel association between an endemic stickleback and a parasitic dinoflagellate. 3: Details of the life cycle. Arch. Protistenkd., 145:165-175.

91. Burkholder, J. M. \& Glasgow, H. B., Jr. (1995) Interactions of a toxic estuarine dinoflagellate with microbial predators and prey. Archiv. Protistenk., 145:177-188.

92. BuckLAND-Nicks, J., Reimchen, T. E. \& Garbary, D. J. (1997) Haidadinium gasterosteophilum gen. et. sp. nov. (Phytodiniales, Dinophyceae), a freshwater ectoparasite on stickleback ( Gasterosteus aculeatus from the Queen Charlotte Islands, Canada. Canadian J. Botany, 75: 1936-1940.

93. BALICK, M. J. (1996) Transforming ethnobotany for the new millennium. Ann. Mo Bot. Gard., 83: 58-66.

94. HAukioja, E. (1999) Bite the mother, fight the daughter. Nature, 401: 22-23

95. Agrawal, A. A., LAFORSCH, C. \& TOLLRIAN, R. (1999) Transgenerational induction of defenses in animals and plants. Nature, 401: 60-63.

96. Thellier, M., Le Sceller, L., Norris, V., Verdus, M. C. \& Ripoll, C.(2000) Longdistance transport, storage and recall of morphogenetic information in plants. The existence of a sort of primitive plant 'memory'. C. R. Acad. Sci. III, 323(1): 81-91.

97. Foyer, C. H. \& Noctor, G. (1999) Leaves in the dark see the light. Science, 284(5414): 599-601.

98. Stebins, G. L. (1942) The genetic approach to problems of rare and endemic species. Madroño, 6: 241-258.

99. Stebbins, G. L. (1980) Rarity and plant species: a synthetic viewpoint. Rhodora, 82:77-86.

100. Gitzendanner, M. A. \& Soltis, P. S. (2000) Patterns of genetic variation in rare and widespread plant congeners. Amer. J. Bot., 87:783-792

101. Newton, A. C., Allnutt, T. R., Gillies, A. C., Lowe, A. J. \& Ennos, R. A. (1999) Molecular phylogeography, intraspecific variation and the conservation of tree species. Trends Ecol. Evol., 14(4): 140-145.

102. SANDERS, I. R. (1999) Evolutionary genetics. No sex please, we're fungi. Nature, 399(6738): 737-739.

103. Brasier, C. (2000) The rise of the hybrid fungi. Nature, 405(6783): 134-135. 


\section{Botánica y Evolución}

104. Doolittle, R. F., Feng, D. F. \& Cho, G. (1999) Determining divergence times with protein clocks. Biol Bull, 196(3): 356-357; discussion 357-358.

105. Zillig, W., Klenk, H. P., Palm, P., Leffers, H., P hler, G., Gropp, F., Garrett, R. A. (1989) Did eukaryotes originate by a fusion event? Endocytobiosis Cell Res., 6:125.

106. Gupta, R. S. \& Golding, G. B. (1996) The origin of the eukaryotic cell. TIBS, 21: 166-171.

107. Martin, W. \& Müller, M. (1998) The hydrogen hypothesis for the first eukaryote. Nature, 392(6671):37-41

108. KATZ, L. A. (1998) Changing perspectives on the origin of eukaryotes. TREE, 13(12) 493-497.

109. Lopez-Garcia P. \& Moreira D. (1999) Metabolic symbiosis at the origin of eukaryotes. TIBS, 24(3):88-93

110. Karlin, S., Brocchieri, L., Mrázek, J., Campbell, A. M.\& Spormann, A. M. (1999) A chimeric prokaryotic ancestry of mitochondria and primitive eukaryotes. Proc. Natl. Acad. Sci. USA, 96(16): 9190-9195.

111. Woese, C. (1998) The universal ancestor. Proc. Natl. Acad. Sci. USA, 95(12):68546859 .

112. Berg, O. G. \& Kurland, C. G. (2000) Why mitochondrial genes are most often found in nuclei. Mol. Biol. Evol., 17(6): 951-961.

113. Morden, C. W., Delwiche, C. F., Kuhsel, M. \& Palmer, J. D. (1992) Gene phylogenies and the endosymbiotic origin of plastids. BioSystems 28:75-90.

114. Hallick, R. B., Hong, L., Drager, R. G., Favreau, M. R., Monfort, A., Orsat, B., SPIElmann, A. \& STUTZ, E. (1993) Complete sequence of Euglena gracilis chloroplast DNA. Nucleic Acids Res., 21(15): 3537-3544.

115. McFadden, G. I., Gilson, P. R., Hofmann, C. J. B. , Adcock, G. J. \& Maier, U. G. (1994) Evidence that an amoeba acquired a chloroplast by retaining part of an engulfed eukaryotic alga. Proc. Natl. Acad. Sci. USA, 91:3690-3694.

116. Maier, U. G., Fraunholz, M., Zauner, S., Penny, S., Douglas, S. (2000) A nucleomorph-encoded CbbX and the phylogeny of RuBisCo regulators. Mol. Biol. Evol., 17(4): 576-583.

117. Greenwood, A. D. (1974). The Cryptophyta in relation to phylogeny and photosynthesis. in SANDERS, J. V. \& GoodCHILD, D. J., eds., Electron Microscopy, vol. 2. pp. 566-567. Griffin, Netley.

118. Fujiwara, S., Sawada, M., Someya, J., Minaka, N., Kawachi, M. \& Inouye, I. (1994) Molecular phylogenetic analysis of rbcL in the Prymnesiophyta. J. Phycol., 30: 863871.

119. GIBBS, S. P.(1981) The chloroplasts of some algal groups may have evolved from endosymbiotic eukaryotic algae. Ann. N. Y. Acad. Sci., 361: 193-207.

120. Bhattacharya, D., \& Medlin, L. (1995) The phylogeny of plastids: A review based on comparisons of small-subunit ribosomal RNA coding regions. J. Phycol., 31(4): 489-498.

121. HibBeRD, D. J. (1986) Ultrastructure of the Chrysophyceae- phylogenetic implications and taxonomy. in Kristiansen, J. \& Andersen, R. A., eds., Chysophytes: aspects and problems. pp. 23-36. Cambridge Univ. Press. Cambridge.

122. Wilhelm, C., Müller, A. M., Borstelman, B. \& Schnetter, R. (1991) The pigment composition of Chlorarachnion reptans and of Cryptochlora perforans (Chlorarachniophyta). Crypt. Bot., 2(2/3): 201-204. 
123. Watanabe, M. M., Takeda, Y, Sasa, T, Inouye, I., Suda, S., Sawaguchi, T. \& ChinaRA, M. (1987) A green dinoflagellate with chlorophylls a and b: Morphology, fine structure of the chloroplast and chlorophyll composition. J. Phycol., 23(2): 382-389.

124. Wilcox, L. W. \& Wedemayer, G. J. (1984) Gymnodinium acidotum Nygaard (Pyrrophyta), a dinoflagellate with an endosymbiotic cryptomonad. J. Phycol., 20(2): 236-242.

125. Wilcox, L. W. \& Wedemayer, G. J. (1985) Dinoflagellate with blue-green chloroplasts derived from an endosymbiotic eukaryote. Science, 227: 192-194.

126. Zhang Z, Green B. R, Cavalier-Smith T. (1999) Single gene circles in dinoflagellate chloroplast genomes. Nature, 400(6740):155-9.

127. Tengs, T., Dahlberg, O. J., Shalchian-Tabrizi, K., Klaveness, D., Rudi, K., DelwiCHE, C. F., JAKOBSEN, K. S. (2000) Phylogenetic analyses indicate that the 19'Hexanoyloxy-fucoxanthin-containing dinoflagellates have tertiary plastids of haptophyte origin. Mol. Biol. Evol., 17(5):718-729.

128. Williamson D. H., Gardner M. J., Preiser P., Moore D. J., Rangachari K., Wilson R. J. (1994) The evolutionary origin of the $35 \mathrm{~kb}$ circular DNA of Plasmodium falciparum: new evidence supports a possible rhodophyte ancestry. Mol Gen Genet 243: 249-252.

129. Williamson, D. H., Gardner, M. J., Preiser, P., Moore, D. J., Rangachari, K. \& Wilson, R. J. (1994) The evolutionary origin of the $35 \mathrm{~kb}$ circular DNA of Plasmodium falciparum: new evidence supports a possible rhodophyte ancestry. Mol Gen Genet, 243(2): 249-252.

130. Tibell, L. (1998) Practice and prejudice in lichen classification. Lichenologist, 30:439-453.

131. Remy, W., TAYloR, T. N., HASS, H. \& KerP, H. (1994) Four hundred-million-year-old vesicular arbuscular mycorrhizae. Proc. Natl. Acad. Sci. USA, 91(25): 11841-11843.

132. Gianinazzi-Pearson, V. (1996) Plant cell responses to arbuscular mycorrhizal fungi: Getting to the roots of the symbiosis. The Plant Cell, 8: 1871-1883.

133. Pirozynski, K. A. \& Malloch, D. W. (1975) The origin of land plants: a matter of mycotrophism. Biosystems, 6(3): 153-164.

134. Jorgensen, R. (1993) The origin of land plants: A union of alga and fungus advanced by flavonoids? BioSystems 31, 193-207.

135. KolatTukudy, P. E., Rogers, L.M., Li, D., Hwang, C.S. \& Flaishman, M.A. (1995) Surface signaling in pathogenesis. Proc. Natl. Acad. Sci. USA, 92(10): 4080-4087.

136. Miller, R. M., Hetrick, B. A. D. \& Wilson, G. W. T. (1997) Mycorrhizal fungi affect root stele tissue in grasses. Can. J. Bot., 75: 1778-1784.

137. JEON, K. W. \& LORCH, I. J. (1967) Unusual intra-cellular bacterial infection in large, free-living amoebae. Exp. Cell Res., 48(1): 236-240.

138. LORENZ, M. G. \& WACKERNAGEL, W. (1994) Bacterial gene transfer by natural genetic transformation in the environment. Microbiol. Rev., 58(3): 563-602.

139. Heinemann, J. A. (1991) Genetics of gene transfer between species. Trends Genet., 7(6): 181-186.

140. Maynard Smith, J., Dowson, C. G. \& Spratt, B. G. (1991) Localized sex in bacteria. Nature 349(6304): 29-31.

141. Frost, L. S. (1992) Bacterial conjugation: everybody's doin'it. Can. J. Microbiol., 38 : 1091-1096.

142. ElLIS, J. (1992) Promiscuous DNA-chloroplast genes inside plant mitochondria. $N a$ ture, 299(5885): 678-679. 


\section{Botánica y Evolución}

143. Thorsness, P. E. \& WeBer, E. R. (1996) Escape and migration of nucleic acids between chlroplasts, mitochondria and the nucleus. Int. Rev. Cytol., 165: 207-234.

144. Reith, M. \& Munholland, J. (1993) A high-resolution gene map of the chloroplast genome of the red alga Porphyra purpurea. Pl. Cell, 5(4): 465-475.

145. Brennicke, A., Grohman, L., Hiesel, R., Knoop, V. \& Schuster, W., (1993) The mitochondrial genome on its way to the nucleus: different stages of gene transfer in higher plants. FEBS Lett., 325(1-2): 140-145.

146. Gray, M. W., Burger, G. \& LANG, B. F. (1999) Mitochondrial evolution. Science, 283(5407): 1476-1481.

147. Syvanen, M. (1994) Horizontal gene transfer: evidence and possible consequences. Annu. Rev. Genet., 28: 237-261.

148. Douglas, A. E. (1989) Mycetocyte symbiosis in insects. Biol. Rev., 16(4): 409-439.

149. PENNISI, E. Is it time to uproot the tree of life? Science, 284(5418): 1305-1307.

150. Cho, Y., Qiu, Y. L., Kuhlman, P. \& Palmer, J. D. (1998) Explosive invasion of plant mitochondria by a group I intron. Proc. Natl. Acad. Sci. USA, 95(24): 14244-14249.

151. REDfield, R. J. (1999) The problem of the evolution of sex. In Evolution: a molecular point of view. Proceedings of a workshop. Woods Hole, Massachusetts, USA. 2426 October 1997. Biol Bull 1999 196: 303-420

152. Fuhrman, J. A. (1999) Marine viruses and their biochemical and ecological effects. Nature 399:541-548

153. SCHWEMmLER, W. (1997) Eukaryotism and Symbiosis. Intertaxonic combination versus symbiotic adaptation. Endocytobiology VI. Updated Proceedings of the Sixth International Colloquium on Endocytobiology and Symbiosis, Tübingen, September 610, 1995. H. E. A. Schenk, R. G. Herrmann, K. W. Jeon, N. E. Müller, W. SCHWEMmLeR (eds.). Springer, Berlin, Heidelberg, New York (1997).

154. SAPP, J. (1994) Evolution by Association. A History of Symbiosis. Oxford University Press, N. York. 